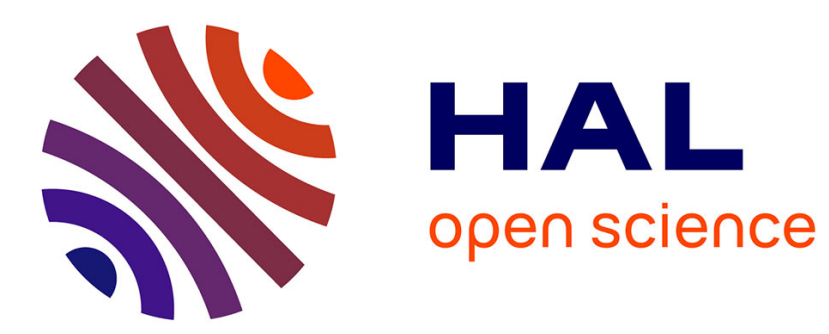

\title{
Silicon-Based Dielectric Metamaterials: Focus on the Current Synthetic Challenges
}

Maria Letizia De marco, Sanaa Semlali, Brian Korgel, Philippe Barois, Glenna

\author{
L. Drisko, Cyril Aymonier
}

\section{To cite this version:}

Maria Letizia De marco, Sanaa Semlali, Brian Korgel, Philippe Barois, Glenna L. Drisko, et al.. Silicon-Based Dielectric Metamaterials: Focus on the Current Synthetic Challenges. Angewandte Chemie International Edition, 2018, 57, pp.2-13. 10.1002/anie.201709044 . hal-01717326

\section{HAL Id: hal-01717326 \\ https://hal.science/hal-01717326}

Submitted on 12 Jun 2020

HAL is a multi-disciplinary open access archive for the deposit and dissemination of scientific research documents, whether they are published or not. The documents may come from teaching and research institutions in France or abroad, or from public or private research centers.
L'archive ouverte pluridisciplinaire HAL, est destinée au dépôt et à la diffusion de documents scientifiques de niveau recherche, publiés ou non, émanant des établissements d'enseignement et de recherche français ou étrangers, des laboratoires publics ou privés. 
Silicon-Based Dielectric Metamaterials: Focus on the Current Synthetic Challenges

Maria Letizia De Marco, Sanaa Semlali, Brian A. Korgel, Philippe Barois, Glenna L. Drisko,* and Cyril Aymonier* 

ability to bend, focus, completely reflect, transmit, or absorb an incident wave front. Optically active metamaterials in particular could be used for applications ranging from $3 D$ information storage to photovoltaic cells. Silicon (Si) particles are some of the most promising building blocks for optically active metamaterials, with high scattering efficiency coupled to low light absorption for visible frequencies. However, to date ideal Si building blocks cannot be produced by bulk synthesis techniques. The key is to find a synthetic route to produce $\mathrm{Si}$ building blocks between $75-200 \mathrm{~nm}$ in diameter of uniform size and shape, that are crystalline, have few impurities, and little to no porosity. This Review provides a theoretical background on Si optical properties for metamaterials, an overview of current synthetic methods and gives direction towards the most promising routes to ideal Si particles for metamaterials.

\section{Introduction}

A wide variety of technologies harvest, manipulate and generate light, such as energy production, communication, the entertainment industry, medical diagnosis and treatment, sensing and manufacturing. Metamaterials offer optical properties that do not exist in natural materials. They can be engineered by arranging optically small particles to obtain a desired electromagnetic behavior. This Review focuses on metamaterials composed of silicon (Si) particles. These particles, often called meta-atoms, have a particular resonant electromagnetic response to light. The metamaterial properties may ultimately be obtained via the collective electromagnetic behavior of the meta-atoms, ${ }^{[1]}$ however, the individual light-scattering of the meta-atoms must be carefully engineered by controlling the composition, size, shape, density and crystallinity.

Smith et al. demonstrated in 2000 that induced resonant currents may generate a strong magnetic polarization in response to the magnetic field of an electromagnetic wave. ${ }^{[2]}$ This report broke the long-accepted rule that magnetism is ineffective at $\mathrm{GHz}$ frequencies and above. Unprecedented extraordinary optical properties requiring optical magnetism such as negative refractive index suddenly became conceivable, and were achieved shortly after in the microwave range ${ }^{[3,4]}$ Such properties lead to super-lensing and transformation optics, making it possible to envision applications, such as cloaking or optical computing. By miniaturizing metaatoms, the operating frequencies were decreased from microwaves to the limits of the visible spectrum. ${ }^{[5]}$

Meta-atoms that are active in the visible portion of the spectrum must demonstrate either plasmonic or Mie resonance. Because of the intense interaction with the electric portion of electromagnetic radiation through localized surface plasmon resonances, gold and silver nanoparticles were the focus of early metamaterial designs. Through a precise spatial arrangement of plasmonic nanoparticles, artificial optical magnetism has been achieved in visible light through both top-down fabrication ${ }^{[6-10]}$ and bottom-up self-assembly. ${ }^{[11-14]}$

However, despite the undeniable early success of plasmonic systems in generating novel optical properties, it rapidly became clear that the optical losses inherent to plasmonic resonances constitute a severe limitation for the realistic application of metamaterials. Optical losses not only spoil the amplitude of the resonances, but also result in strong light absorption, hence making optical devices inefficient. All-dielectric metamaterials overcome these problems, providing an alternative to plasmonic devices. ${ }^{[15]}$ The high value of the real part $n$ of the refractive index $N=n+i k$, in combination with a relatively low absorption coefficient $k$ compared to plasmonics (Figure 1), leads to low losses: the losses of $\mathrm{Si}$ are 10 to 500 times lower than silver across the visible range. These conditions make $\mathrm{Si}$ one of the best

[*] M. L. De Marco, Dr. S. Semlali, Dr. G. L. Drisko, Dr. C. Aymonier CNRS, Université de Bordeaux, Bordeaux INP, ICMCB, UMR 5026 33600 Pessac (France)

E-mail: Glenna.Drisko@icmcb.cnrs.fr Cyril.Aymonier@icmcb.cnrs.fr

Dr. P. Barois

CNRS, Université de Bordeaux, CRPP, UMR 5031

33600 Pessac (France)

Prof. B. A. Korgel

McKetta Department of Chemical Engineering and Texas Materials Institute, The University of Texas at Austin

Austin, TX, 78712 (USA)

iD

The ORCID identification number(s) for the author(s) of this article can be found under: https://doi.org/10.1002/anie.201709044. 
candidates for metamaterials, exceeding the efficiency of meta atoms based on plasmonic silver and gold.

To show visible scattering, Si meta atoms should fulfill a number of requirements. The particles should be pure in composition, monodisperse in shape and size, crystalline, non porous and have a diameter approximately between 80 and $280 \mathrm{~nm} \cdot{ }^{[19,20]}$ We will discuss the importance of each of these factors, as well as the effects of deviating from the ideal case.

The synthesis of $\mathrm{Si}$ particles with the aforementioned requirements represents a long standing challenge. Since the first observation of visible photoluminescence in porous $\mathrm{Si},{ }^{[21]}$ great efforts have been made to produce $\mathrm{Si}$ nanomaterials with controlled size, phase and morphology. A variety of synthesis techniques has been explored to produce $\mathrm{Si}$ nano structures for anodes in lithium ion batteries, ${ }^{[22]}$ light emitting quantum dots (QDs), ${ }^{[23]}$ light harvesting devices, ${ }^{[24]}$ and drug delivery systems. ${ }^{[25]}$

Past Reviews on $\mathrm{Si}$ have focused on $\mathrm{Si}$ exhibiting luminescent properties, ${ }^{[25,26]}$ or as possible anodes for lithium batteries. ${ }^{[22]}$ To date, all the Reviews and textbooks addressing

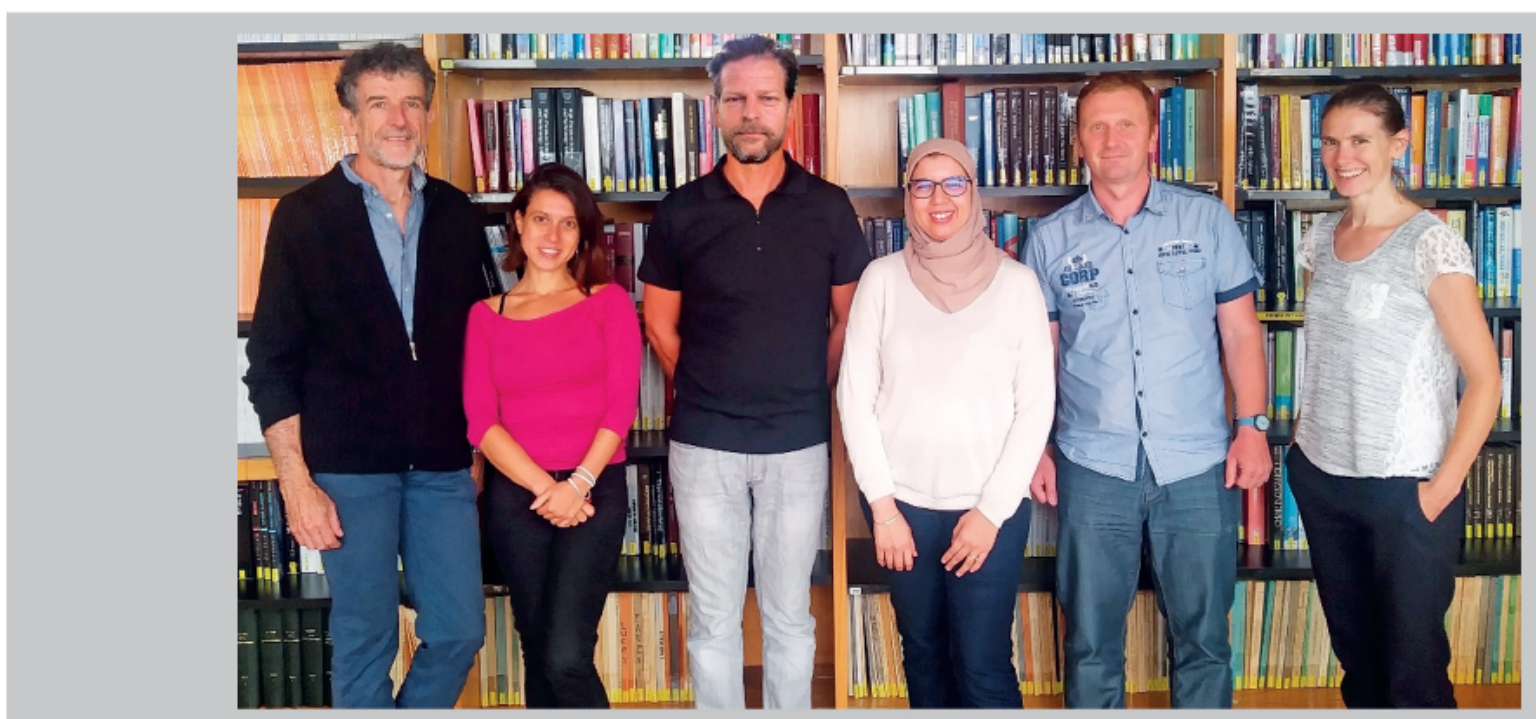

The authors (left to right): Philippe Barois, Maria Letizia De Marco, Brian A. Korgel, Sanaa Semlali, Cyril Aymonier, Glenna L. Drisko

Maria Letizia De Marco is a Ph.D. candidate at the University of Bordeaux. She is currently working on the synthesis of dielectric particles in supercritical media, for application in optical metamaterials. In 2015 she graduated with honors in Physical and Inorganic Chemistry at Sapienza University of Rome.

Sanaa Semlali is a post doc fellow at Institut de Chimie de la Matière Condensée de Bordeaux. She works on silicon synthesis for optically active metamaterials. She obtained her Ph.D. thesis jointly from the Laboratoire de Chimie de la Matière Condensée de Paris and the Institut des Sciences Analytiques et Physico Chimique pour l'Environnement et les Matériaux in 2013. She has worked on diverse topics including the synthesis of nanomaterials, mesoporous thin films, catalysis and photocatalysis.

Brian A. Korgel received his PhD in Chemical Engineering from UCLA in 1997 and was a post doctoral fellow at University College Dublin, Ireland, in the Department of Chemistry. He works on nano and mesoscopic materials chemistry and complex fluids, tackling problems in energy storage, chemical transformations, energy harvesting and conversion, and medicine. He is the Edward S. Hyman Chair in Engineering and T. Brockett Hudson Professor of Chemical Engineering at the University of Texas at Austin, has co founded two companies, Innovalight and Piñon Technologies, and received honors including the 2012 Professional Progress Award from the American Institute of Chemical Engineers (AlChE).

Philippe Barois is a full time senior researcher for the CNRS in the Centre de Recherche Paul Pascal, which he directed for 5 years. He obtained a Ph.D. from the University of Bordeaux on phase transition theories in liquid crystals. He was a post doctorate researcher at the Australian National University in Canberra where he studied self assembled phases of surfactants in ternary systems. Most of his research has been devoted to structural investigations of complex fluids like liquid crystals. In particular, he developed the technique of resonant $X$ ray scattering, which he applied to soft condensed matter systems. His current research concerns the experimental demonstration of optical magnetism in visible light.

Glenna L. Drisko is a full time researcher for the CNRS, specializing in nanoparticle synthesis, especially silicon particle synthesis for metamaterials. She received a L'Oreal Unesco For Women in Science award for her vision in optically active metamaterials. She completed her Ph.D. in 2010 from The University of Melbourne where she studied morphological control of sol gel derived materials using organic templates. She was a post doctorate researcher in the Collegge de France studying the self assembly and optical properties of structured thin films and the crystallization of mesostructured silica. She is passionate about exploring synthetic mechanisms and self assembly.

Cyril Aymonier is a senior full time CNRS researcher at the Institute of Condensed Matter Chemistry of Bordeaux. He obtained his Ph.D. from the University of Bordeaux in Chemical Engineering on supercritical water oxidation in 2000. Afterwards he spent two years in Freiburg im Breisgau (Germany) where he developed new routes to prepare organic/inorganic nanocomposites and then joined the CNRS in 2002. His current research interests include the study of chemistry and nucleation and growth in supercritical fluids applied to the design of advanced and multifunctional nanostructured materials. He was awarded the CNRS bronze medal. 


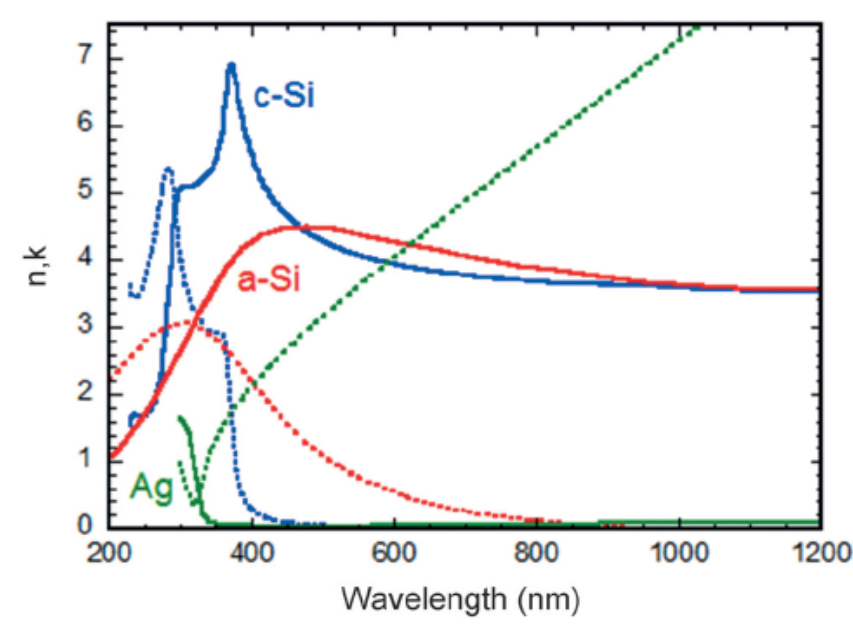

Figure 1. The real ( $n$, solid lines) and imaginary ( $k$, dotted lines) parts of the refractive index $N(\lambda)$ of crystalline $\mathrm{Si}$ (blue) and amorphous $\mathrm{Si}$ (red). The refractive index of silver (green) is shown for reference. The data used in the graph are reproduced from Refs. [16 18].

$\mathrm{Si}$ for use in metamaterials discuss the fundamental optics behind its visible light scattering. ${ }^{[15,27,28]}$

Herein we present silicon based metamaterials from a chemist's perspective, disscussing the synthesis of $\mathrm{Si}$ particles in view of their potential application to metamate rials. We will address the most promising bottom up tech niques, as well as individual experimental parameters, particle nucleation and growth, crystallization, densification, and surface functionalization. We will clarify for physicists what can realistically be produced and give direction to the chemists who synthesize dielectric meta atoms. The concept of all dielectric metamaterials built from $\mathrm{Si}$ meta atoms is a relatively new one, ${ }^{[27]}$ necessitating an overview of the state of the art to lead the scientific community towards a techno logical breakthrough in all dielectric metamaterials.

\section{Theoretical background}

Gustav Mie addressed the interaction of electromagnetic waves with spherical homogeneous particles of arbitrary size many years ago. ${ }^{[2]}$ It consists of absorption (heat dissipation inside the sphere) and emission of a scattered field towards external space. The scattering power of the particle is quantified by the scattering cross section, defined as the ratio of the total scattered power (in Watts) to the irradiance of the incident field (in Watts per unit area). It has dimensions of area and is often usefully normalized by the geometrical cross section $\pi \mathrm{R}^{2}$ to yield the dimensionless scattering efficiency. ${ }^{[30]}$ This scattering efficiency can be larger than one, meaning that the particle resonator interacts more with light than its simple geometrical optics would suggest. The Mie theory expands the scattered light in a series of super imposing multipolar contributions. For particles smaller than the wavelength of the impinging light, the dominant contri butions are dipolar, followed by quadrupolar, and so on. Under particular conditions, electromagnetic field resonances occur inside the sphere in response to the incident light, which may result in very high scattering efficiencies. Although the algebra of the Mie theory is tedious, the origin of the Mie resonances is clear if we see the sphere as an optical cavity. In a flat optical cavity of thickness $d$ (where $d$ is the distance between two flat reflecting mirrors) constructive interference occurs when the cavity contains an integer number of half wavelengths $\left(d=\frac{m \lambda}{2}\right)$. Similarly, Mie resonances occur when the wavelength $\lambda_{P}$ inside the particle is comparable to the diameter $d$ of the dielectric sphere (Figure 2). A first dipolar resonance displaying a maximum in the magnetic field inside the sphere is observed for $\lambda_{p} \approx d$. A second dipolar resonance of electric nature occurs when $\lambda_{p} \approx \frac{d}{2} \cdot{ }^{[15,31,32]}$ Other terms of higher multipolar order in the Mie expansion generate resonances at shorter wavelengths but with decreasing strength as the scattering efficiency decreases with multipolar order.

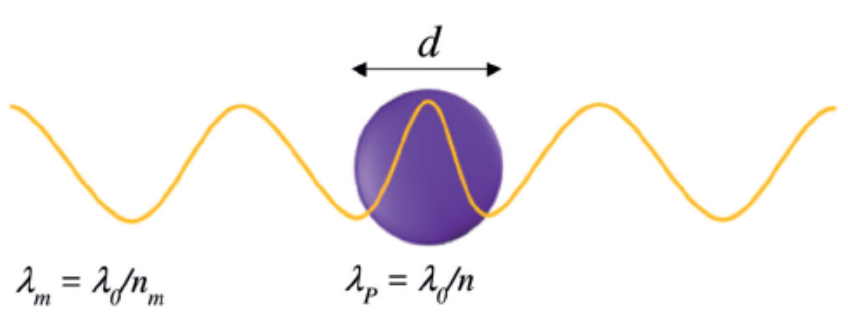

Figure 2. When an electromagnetic wave passes from a host matrix with refractive index $n_{m}$ to an inclusion of higher index $n$, its wave length becomes shorter by a factor $\frac{\lambda_{m}}{\lambda_{p}} \quad \frac{n}{n_{m}}$. The first Mie resonances occur when the wavelength inside the spherical particle $\lambda_{p} \quad \frac{\lambda_{0}}{n}$ is comparable to its size $d$. $\lambda_{0}$ is the vacuum wavelength. ${ }^{[1]}$ For a bulk composite material made of such inclusions, the optical homogeneity condition $d \lambda_{p} \ll \lambda_{m}$ requires $n \geqslant n_{m}>1$.

Figure 3 illustrates the distribution of the electric and magnetic fields in space for the dipolar Mie resonances. At the magnetic Mie resonance, a circular polarization current is induced within the particles in response to the incident field, this current generates a magnetic dipole, perpendicular to the incident electric field, oscillating at the same frequency as the excitation wavelength (Figure 3, top). ${ }^{[15,20]}$ Similar field maps are found for the electric Mie resonance by switching the roles of the electric and magnetic field, hence resulting in strong scattering of the electric dipole (Figure 3, bottom).

The condition for a Mie resonance $\lambda_{P} \approx d$ is in contra diction with the homogeneity condition of a bulk material which requires meta atoms to be much smaller than the wavelength $\lambda_{m}$ in the matrix. These two conflicting conditions can be simultaneously satisfied if the real part $n$ of the refractive index of the material constituting the meta atom is significantly larger than the index of the matrix since da $\frac{d}{\lambda_{m}} \sim \frac{\lambda_{p}}{2 \lambda_{m}}=\frac{n_{m}}{2 n} \ll 1$ if $n \gg n_{m}>1$ (Figure 2). In the visible range, crystalline $\mathrm{Si}$ appears to be the best candidate among all known materials because of a high refractive index $n$ near 4 across the visible range (Figure 1). Moreover, the low values of the imaginary part $k$ (relating to light absorption) warrant a sharp and intense resonant response in the visible. Intense Mie resonances have been simulated and observed in silicon spheres. ${ }^{[31,33]}$ 


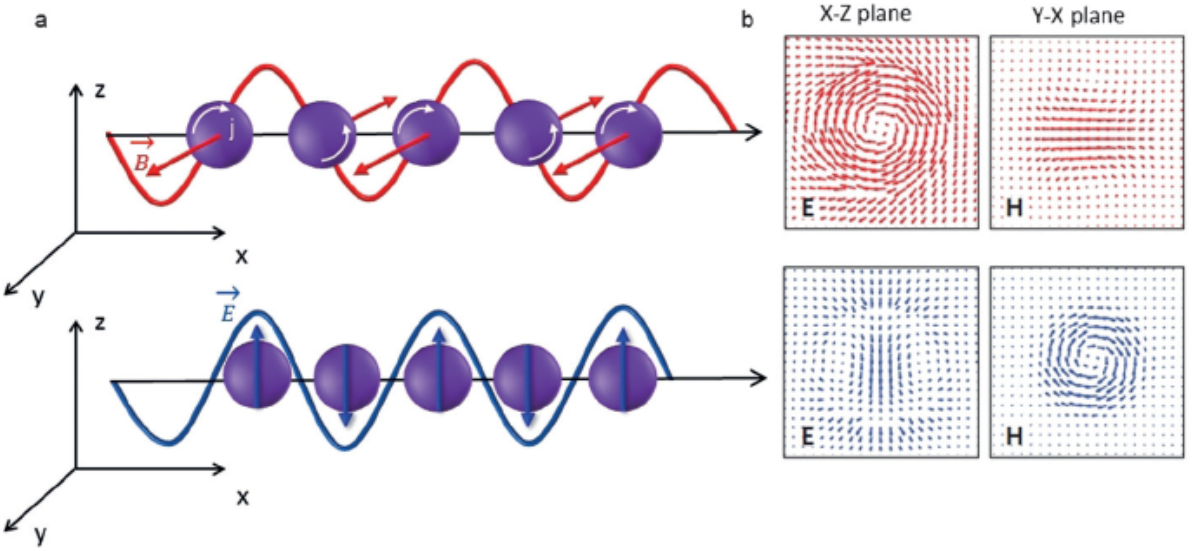

Figure 3. a) The magnetic dipole (top) and electric dipole (bottom) oscillating with the incident electric field of light. b) The field distributions calculated inside the particle for the magnetic dipole resonance (top) and the electric dipole resonance (bottom). The arrows of the field distribution indicate the orientation of the induced electric or magnetic field within the particle for each mode. Adapted with permission from Ref. [15].
We will address Si spheres, which can be readily obtained using bottom up synthesis and provide strong Mie resonances in the visible spectrum for diameters between 75 $200 \mathrm{~nm}$.

\subsection{Size and Crystallinity}

There is a quasi linear dependence of the wavelength of the Mie resonances on the $\mathrm{Si}$ particle diameter. Simulated scatter ing spectra (Figure 4) show that efficient visible light scattering occurs for particles between $75200 \mathrm{~nm}$. As the particle diam eter increases, the magnetic and electric resonances redshift (Figure 4). This size dependence is a strong advantage over plasmonic nanoparticles since it enables fine tuning of the resonance wavelength. It is also a strong constraint since size poly

\section{Structure-Property Relationships in Si Particles: Theoretical Modeling and Experimental Results}

The particle properties, for example, size, shape, porosity, and crystallinity, affect the scattering behavior of $\mathrm{Si}$ meta atoms. This section presents structure property relationships derived from the well established Mie theory of spherical particle scattering, ${ }^{[30]}$ along with some exemplifying exper imental results. The influence of the degree of crystallinity, porosity and the thickness of the oxide passivating coating are especially important.
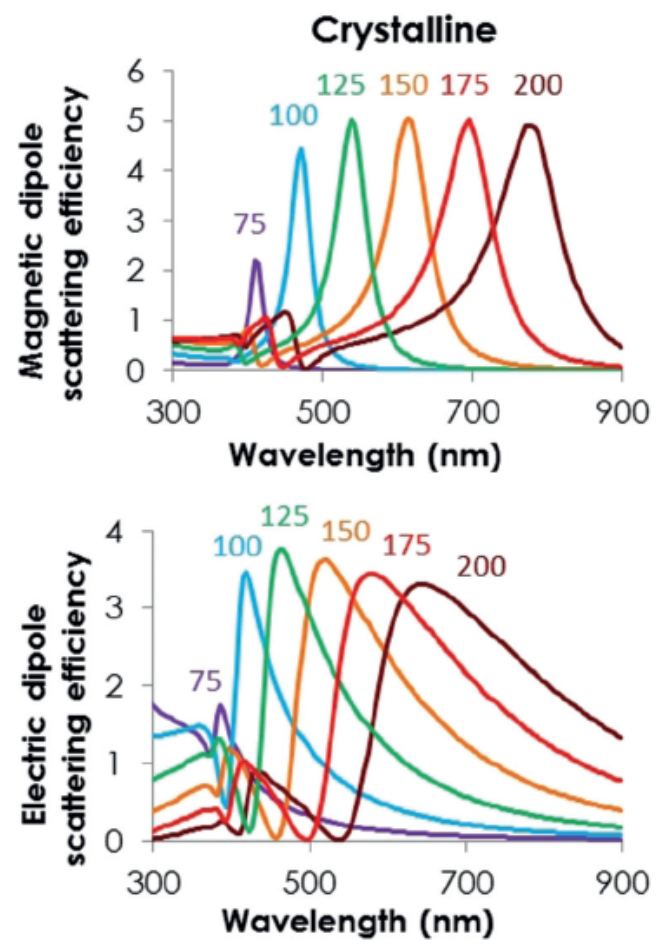

dispersity will reduce the wavelength selectivity. Note how ever that broadband applications may accept some degree of size dispersion.

In the case of amorphous $\mathrm{Si}$ particles, the electric and magnetic scattering peaks are slightly redshifted and less intense than for crystalline $\mathrm{Si}$ particles of the same diameter. The difference in the scattering spectra arises from differ ences in the imaginary part $k(\lambda)$ of the refractive index. For crystalline $\mathrm{Si}, k(\lambda)$, which corresponds to the absorption coefficient, falls off quickly above $400 \mathrm{~nm}$ (Figure 1). ${ }^{[16]}$ However, $k(\lambda)$ decays slowly for amorphous $\mathrm{Si}$ and vanishes
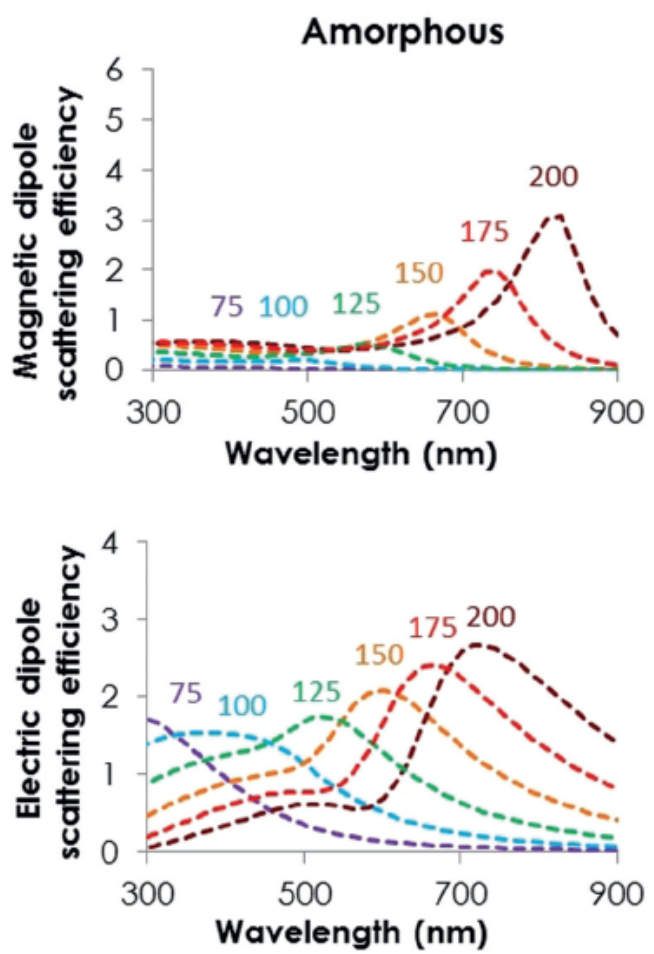

Figure 4. The magnetic and electric dipole scattering are computed using the Mie theory for spherical crystalline (left) and amorphous (right) Si particles with diameters ranging from 75 to $200 \mathrm{~nm}$. The host medium is water. 

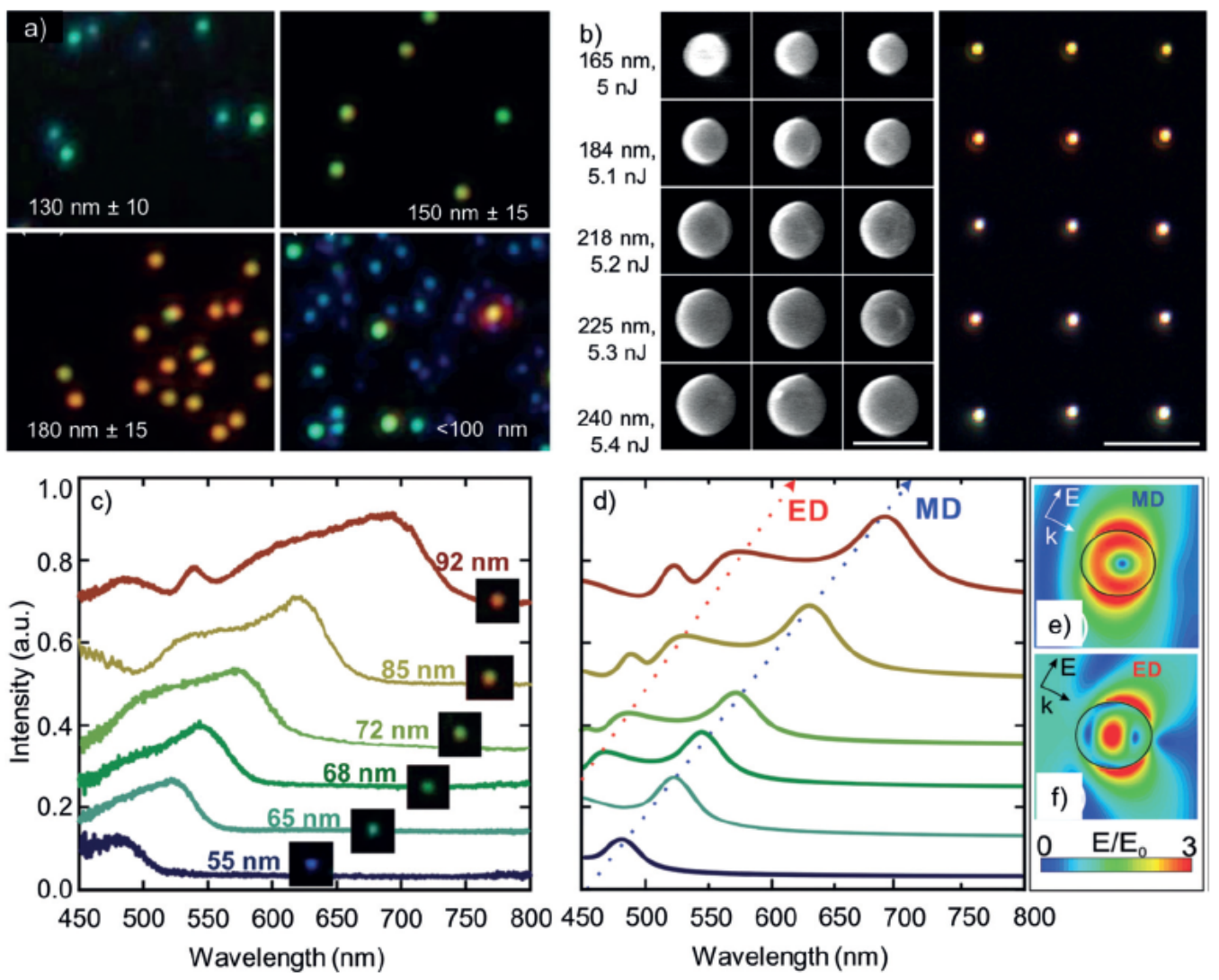

Figure 5. a) The color of emitted light as a function of Si particle size. The particles are polycrystalline. b) SEM image of evaporated Si spheres ranging in size from $165240 \mathrm{~nm}$. The dark field optical microscopy images show how the optical response changes with particle diameter. c) Experimental and d) theoretical spectra of individual particles scattering $p$ polarized light from an incident angle of $65^{\circ}$. Simulated electric field distributions for incident wavelengths of e) $635 \mathrm{~nm}$ and f) $525 \mathrm{~nm}$ within a Si particle. Images reproduced with permission from Refs. [33, 34].

only at the infrared limit above $800 \mathrm{~nm} .{ }^{[17]}$ This consideration should not discourage the chemist who manages to produce large (ca. $100 \mathrm{~nm}$ ) monodisperse amorphous Si beads, which, even if not ideal, exceed the efficiency of magnetic meta atoms based on plasmonic materials such as silver and gold. ${ }^{[13,14]}$ Moreover, as amorphous Si has lower light absorp tion for higher frequencies, and large, amorphous $\mathrm{Si}$ particles are interesting for infrared applications.

The theoretical results presented so far are confirmed by several experimental studies. Kutznetsov and co workers produced $\mathrm{Si}$ particles of various sizes by femto second laser ablation. ${ }^{[20]}$ A laser pulse induced the evaporation of a $\mathrm{Si}$ droplet, where the laser power applied led to a precise $\mathrm{Si}$ droplet diameter. The droplets condensed on a substrate to form $\mathrm{Si}$ particles. Dark field microscopy and scattering spectroscopy of these particles showed the predicted redshift in the scattering wavelength as Si particle diameter increased. Zywietz et al. also used dark field scattering spectroscopy to show a clear redshift in the optical response with increasing particle size (Figure 5b).

Zywietz et al. used laser ablation to produce Si particles of controllable size and degree of crystallinity. ${ }^{[33]}$ The energy irradiated by the laser determines the size of the particles, while irradiation of the as formed particle with one or more successive laser pulses induces partial or total crystallization. By controlling the laser energy and number of pulses, they were able to separately investigate the effect of size and crystallinity. Figure 6 shows the scattering spectra of three particles of the same diameter $(161 \mathrm{~nm})$, but having a different degree of crystallinity (amorphous, $70 \%$ crystalline and fully crystalline). The measured results support the simulated trends: both the magnetic and electric scattering resonances blueshift and increase in intensity with an increasing degree of crystallinity from 0 to $100 \%$.

\subsection{Porosity}

Porosity reduces the real part of refractive index in $\mathrm{Si}$ particles, ${ }^{[35]}$ hence reducing the wavelength ratio $\frac{\lambda_{p}}{d}$. Pores abate the global index of the pure material due to the lower refractive index of the air, water or solvent which fill this space. The extent of this effect depends on the pore volume and the nature of the matter filling the pores. Under atmospheric conditions, it is likely that microporous $\mathrm{Si}$ will have water filling the pores, as it has been shown that a porous material having silanol groups on its surface and a pore diameter of $2 \mathrm{~nm}$ will fill its pores through capillary action at $45 \%$ relative humidity and above. ${ }^{[36]}$ If a humidity free environment is maintained throughout the synthesis and material processing steps, porous $\mathrm{Si}$ will present air filled pores. Both water $(n=1.33)$ and air $(n=1)$, have a lower 


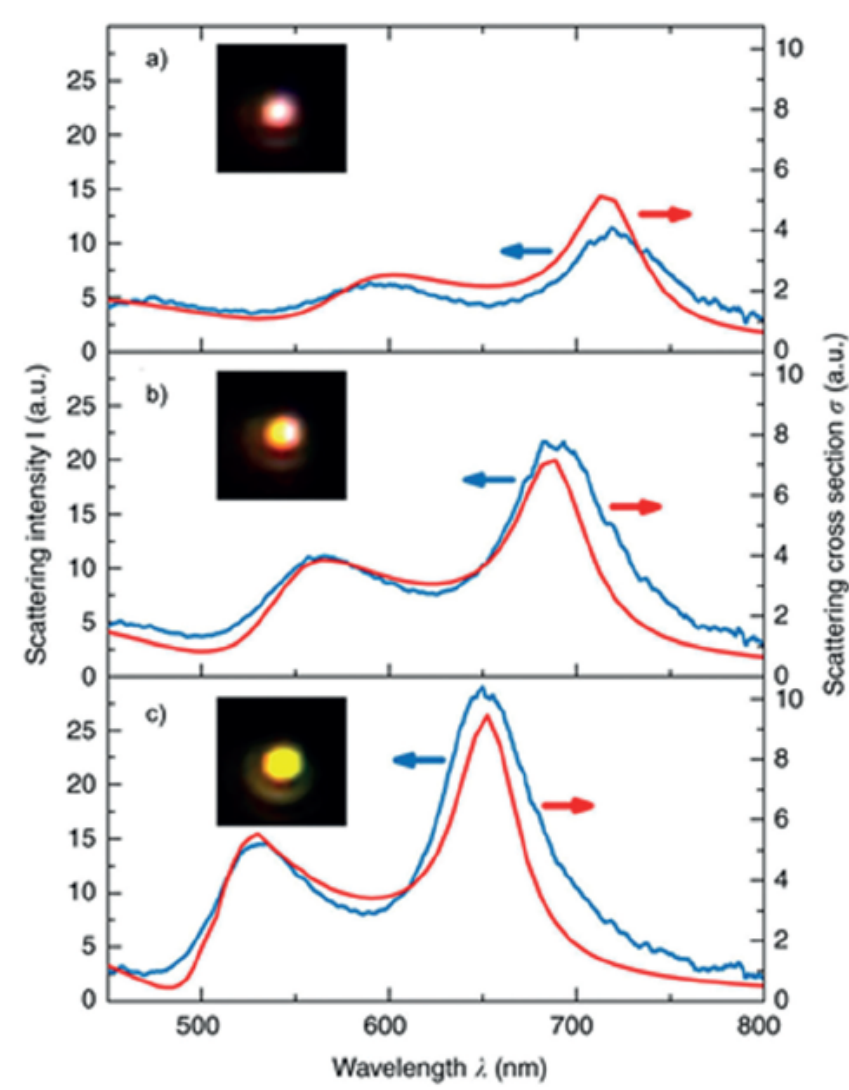

Figure 6. Experimental (blue line) and simulated (red line) scattering spectra for a) amorphous, b) $70 \%$ crystalline and c) fully crystalline $\mathrm{Si}$ particles of the same size $(161 \mathrm{~nm})$, Inset: dark field microscopy images of measured Si particle. Reproduced with permission from Ref. [33].

refractive index than Si. Therefore, compact, dense Si has a higher refractive index with respect to porous $\mathrm{Si}$, and, accordingly, higher scattering efficiency. When designing the synthesis of $\mathrm{Si}$ meta atoms, it is important to consider how

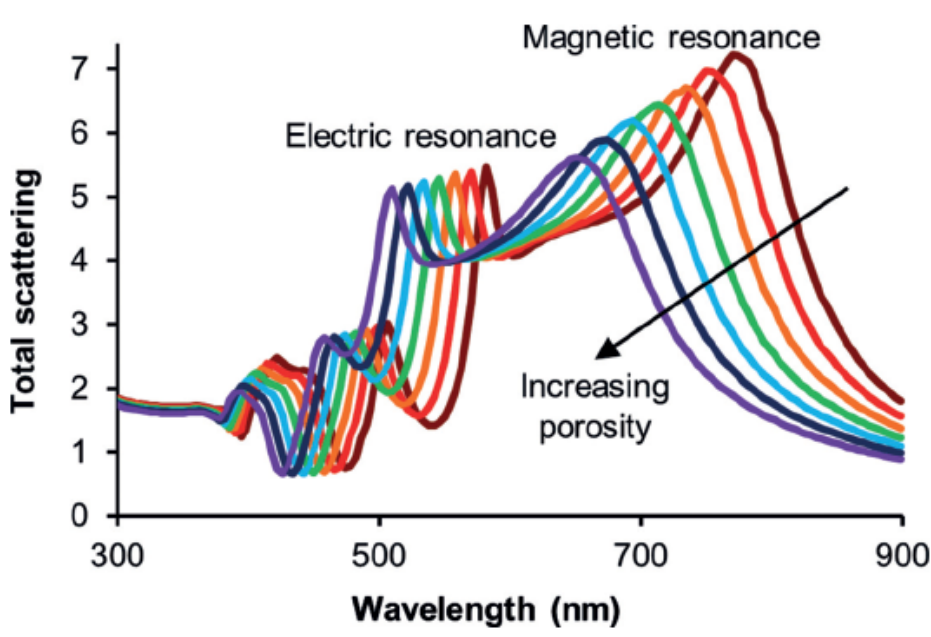

Figure 7. The scattering efficiency shifts as a function of porosity. Scattering by a dense, crystalline Si sphere of $200 \mathrm{~nm}$ is shown in brown. Water was assumed to be filling the pores. A water volume fraction of $5 \%$ (red), $10 \%$ (orange), $15 \%$ (green), $20 \%$ (light blue), $25 \%$ (dark blue), and $30 \%$ (purple) was modelled. porosity affects the scattering properties. We have modelled the effect of porosity, assuming that water is filling the pores and using a simple Maxwell Garnett mixing law (Figure 7). However, the same trend exists for pores full of air. We see that as porosity becomes more significant in a crystalline $\mathrm{Si}$ sphere, the scattering efficiency decreases and the scattering wavelength blueshifts. As we discussed in Section 2, the ratio between the wavelength and the refractive index should be equal to the particle size in order to observe Mie scattering. This condition imposes that the Mie resonances in a porous $\mathrm{Si}$ sphere appear at shorter wavelength with respect to the dense particle. Even so, a Si particle having $30 \%$ porosity still has interesting optical properties! Thus chemists should still test the optical scattering properties of $\mathrm{Si}$ particles that are less than ideal in terms of their density.

\subsection{Surface chemistry}

Surface chemistry is a critical parameter for chemists working in nanomaterials. The optical and electronic proper ties, dispersibility, particle aggregation, stability towards corrosion and degradation are all affected by surface chemis try. Without post synthesis functionalization, Si meta atoms have surfaces passivated with a native layer of $\mathrm{SiO}_{x}$. We simulated the effect of a passivating $\mathrm{SiO}_{2}$ shell on the scattering properties of a $\mathrm{Si}$ particle having a diameter of $100 \mathrm{~nm}$ in water (Figure 8). As the thickness of the passivating film increases, the resonance peaks blueshift and their intensity decreases, which is simply due to a reduction in the core size of crystalline $\mathrm{Si}$ through the growth of an oxide shell. The shell has a refractive index (ca. 1.4) close to the index of water (ca. 1.33) and thus exhibits a minimal optical effect. If, on the other hand, the surrounding medium is air, growing a silica shell around a crystalline $\mathrm{Si}$ sphere of constant radius results in a weak redshift, becoming appreciable for shell thicknesses exceeding several tens of nanometers. Evlyukhin and co workers simulated Si particle arrays with a 10 or $30 \mathrm{~nm}$ oxide coating in air and found a weak redshift of the scattering with respect to arrays of uncoated Si particles. ${ }^{[19]}$

It is safe to consider that a particle of outer radius $R$ and oxide shell thickness $e$ optically behaves like a bare Si sphere of radius $\left(\begin{array}{ll}R & e\end{array}\right)$ in water. This is also true in air for native oxide layers which do not exceed an $e=2$ to $3 \mathrm{~nm} \cdot{ }^{[37]}$ However, an oxide layer thicker than $3 \mathrm{~nm}$ would only be grown if the particles were heated in the presence of oxygen.

Currently, there are no publications reporting the characterization of the Si meta atom surface state. We assume that the surface of meta atoms produced so far by top down ${ }^{[20,33]}$ or bottom up ${ }^{[35]}$ methods are coated with a thin native oxide layer. The formation of an oxide layer can in principle be avoided by functionalizing the $\mathrm{Si}$ surface with stabilizing ligands. In most cases however, this will not be necessary since this surface oxidation has a marginal optical effect on $\mathrm{Si}$ meta atoms having a diameter of hundreds of $\mathrm{nm}$. Moreover, the oxide layer can be usefully exploited to function 


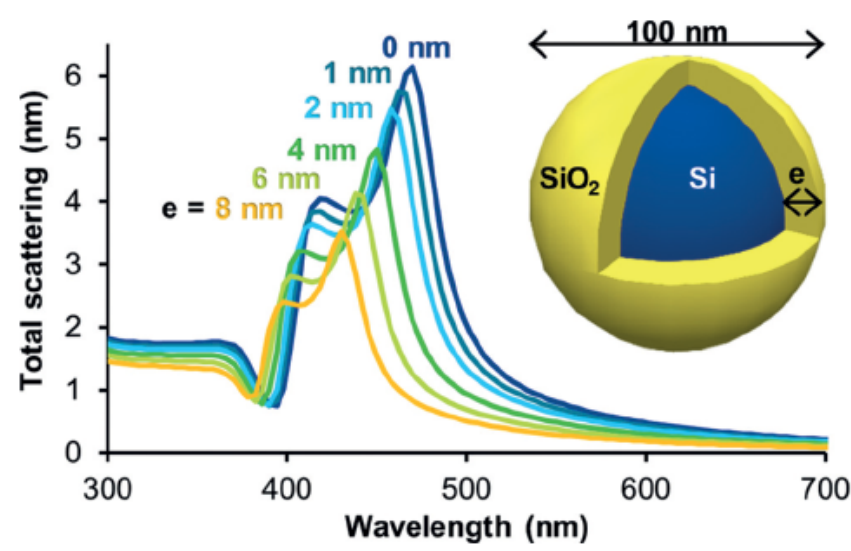

Figure 8. Scattering efficiency computed for a $100 \mathrm{~nm}$ crystalline $\mathrm{Si}$ particle with shell thickness, $e$, transitioning from no passivating

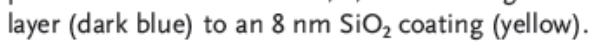

parameter has a substantial effect on the yield and the characteristics of the $\mathrm{Si}$ nanostructures produced. To date, no reports exist correlating the stability of a precursor with the observed properties (size, crystallinity and morphology) of $\mathrm{Si}$ spheres, but trends can be found by a careful study of the literature.

Several $\mathrm{Si}$ precursors have already been used in the literature, all having a differing degree of reactivity. Figure 9 shows some Si precursors used for the synthesis of Si particles and nanowires.

$\mathrm{Lu}$ and co workers investigated the effect of precursor stability by using a series of silanes having 3 to $6 \mathrm{Si}$ atoms. They produced $\mathrm{Si}$ nanorods according to solution liquid solid seeded growth in squalene, at temperatures between 200 and $380^{\circ} \mathrm{C}^{[38]}$ Generally, the reactivity of the precursor increases with increasing the number of $\mathrm{Si}$ atoms. However, the yields

alize the surface. As will be further discussed (see Section 6), the func tionalization step can be carried out in situ or during a post synthesis step.

We have discussed how the par ticle characteristics size, crystallin ity, porosity and surface chemistry affect the optical scattering of $\mathrm{Si}$ meta atoms. Chemists should con sider these structure property rela tionships when designing a synthesis
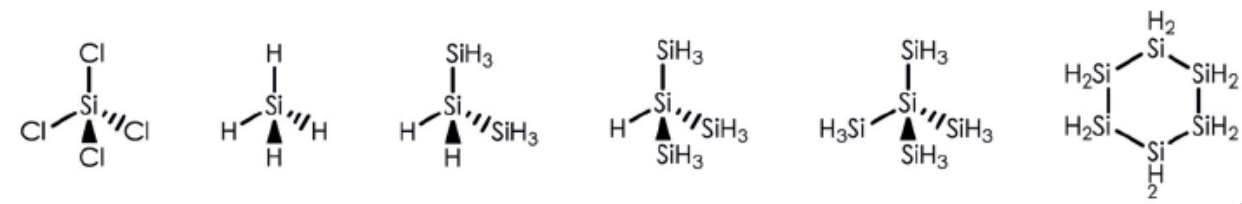
route for the bottom up production of efficient $\mathrm{Si}$ meta atoms. In particular, the size requirement should be met, as strong optical scattering is observed for particles within the range $75200 \mathrm{~nm}$.

\section{Synthetic Techniques and Parameters Affecting Silicon Particle Properties}

Section 3 clearly illustrates how the structural properties of Si particles affect their optical scattering. No one has yet made ideal $\mathrm{Si}$ meta atoms through bottom up chemistry; however, trends exist in the literature that can be extrapo lated to achieve these ideal dielectric meta atoms. By combining the lessons learned from different systems dense, crystalline Si particles of $75200 \mathrm{~nm}$ in diameter should be accessible. In Section 4 we will present the most common precursors used in $\mathrm{Si}$ chemistry, and discuss the most promising synthetic routes towards $\mathrm{Si}$ meta atoms: high temperature reduction, plasma and aerosol techniques, and synthesis in supercritical fluids. We will also examine how individual parameters (i.e. concentration, precursor stability, type of solvent) affect the particle characteristics.

\subsection{Precursor Stability}

The precursor stability depends primarily on the bond dissociation enthalpy and on the decomposition kinetics. This

obtained at a certain temperature with isotetrasilane ( $4 \mathrm{Si}$ atoms) and neopentasilane ( $5 \mathrm{Si}$ atoms) were basically identical. In the case of cyclohexasilane (6Si atoms), the yield was higher than expected based solely on the number of $\mathrm{Si}$ atoms and the reaction temperature. The higher reactivity of cyclohexasilane compared to acyclic silanes is due to both the number of $\mathrm{Si}$ atoms per molecule and the presence of an unsaturation as a result of cyclization. Therefore, an accurate choice of precursor may allow the synthesis of $\mathrm{Si}$ nano structures under milder conditions.

Although we have seen that higher reactivity generally produces higher yields and higher quality Si nanostructures, many factors must be considered. More reactive precursors are typically more dangerous (silane and longer chain silanes are pyrophoric), more difficult to handle, more difficult to acquire and more expensive than tetrachlorosilane.

\subsection{Elevated Temperature Reductive Synthesis of Si Particles}

We discuss in Section 3 that $\mathrm{Si}$ particles should have a diameter ranging between 75 and $200 \mathrm{~nm}$ to exhibit visible light scattering. The elevated temperature reductive synthesis allows the production of particles from a few nanometers up to several micrometers.

Preformed silica can be reduced to $\mathrm{Si}$ via multiple methods by, for instance carbothermal reduction and nitrida tion reduction above $1400^{\circ} \mathrm{C}$. At such a high temperature, nanostructures are lost. As an alternative to these high 

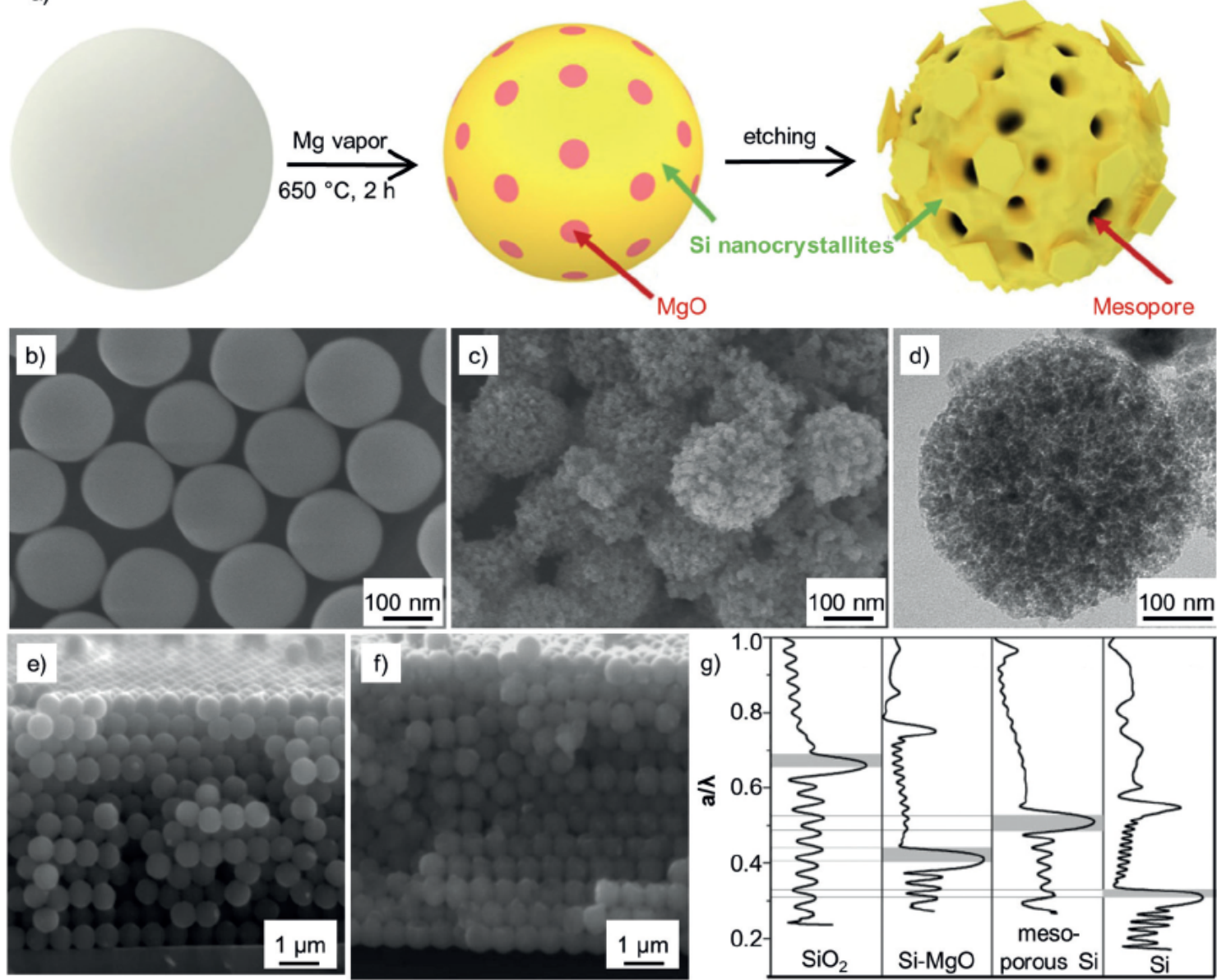

Figure 10. a) Schematic mechanism of magnesium reduction. b),c),e),f) Scanning and d) transmission electron microscopy images of b) $\mathrm{SiO}_{2}$ spheres c),d) Si spheres, e) a $\mathrm{SiO}_{2}$ opal and f) a $\mathrm{Si}$ opal. g) Reflectance spectra of $\mathrm{SiO}_{2}, \mathrm{Si} \mathrm{MgO}$, mesoporous $\mathrm{Si}$, and less porous $\mathrm{Si}$ opals obtained by treating the $\mathrm{Si}$ opals with chemical vapor deposition of $\mathrm{Si}_{2} \mathrm{H}_{6}$. Images taken with permission from Refs. $[44,46,47]$.

temperature methods, metallothermic reduction can be performed using magnesium $\left(600800^{\circ} \mathrm{C}\right),{ }^{[39]}$ sodium $\left(300^{\circ} \mathrm{C}\right),{ }^{[40]}$ or aluminum $\left(700800^{\circ} \mathrm{C}\right) .{ }^{[41,42]}$ By far the most popular reductant is magnesium, in part due to its ease of handling and partly because it is more efficient at reducing all of the silica to $\mathrm{Si}$ while largely maintaining the initial silica structure. However, to our knowledge a side by side compar ison of metals reducing the same silica material has yet to be performed. In the metallothermic reduction technique, silica reduces upon contact with vaporized metal (Figure 10a). This produces an aggregate of $\mathrm{Si}$ and a metal oxide, for example, $\mathrm{MgO}$. Magnesium vapors can reduce nanostructured silica to $\mathrm{Si}$ in the following reaction [Eq. (1)]. ${ }^{[43]}$

$\mathrm{SiO}_{2}(\mathrm{~s})+2 \mathrm{Mg}(\mathrm{g}) \rightarrow \mathrm{Si}(\mathrm{s})+2 \mathrm{MgO}(\mathrm{s}) \quad 245.2 \mathrm{~kJ} \mathrm{~mol}^{1}$

$\mathrm{Mg}_{2} \mathrm{Si}$ is also generated upon an excess of magnesium. The metal oxide is typically washed away using $1 \mathrm{M} \mathrm{HCl}$ and silica is removed using HF.

Porosity is inevitably created when the metal oxide is removed, however, some degree of porosity can be tolerated in meta atoms (Figure 7, see Section 3.2). Unfortunately, the degree of porosity has not been well characterized in $\mathrm{Si}$ spheres. Ibisate et al. ${ }^{[44]}$ decreased the amount of porosity by depositing $\mathrm{Si}_{2} \mathrm{H}_{6}$ via chemical vapor deposition after $\mathrm{Mg}$ treatment. In another example Stöber silica particles between $6200 \mathrm{~nm}$ in diameter were converted to $\mathrm{Si}$ particles using magnesiothermic reduction at $500{ }^{\circ} \mathrm{C}^{[45]}$

Despite the abundant examples of reduced silica struc tures in the literature, the metallothermic approach has several major drawbacks. Firstly, the obtained $\mathrm{Si}$ is not homogenous. Close to the $\mathrm{Mg}$ source, $\mathrm{Mg}_{2} \mathrm{Si}$ is generated instead of $\mathrm{Si}^{\left[{ }^{[48]}\right.}$ Placed at a distance too far from the $\mathrm{Mg}$ source and the sample remains polluted with $\mathrm{SiO}_{2}$. Although both $\mathrm{Mg}_{2} \mathrm{Si}$ and $\mathrm{SiO}_{2}$ can be removed with acids $(\mathrm{HCl}$ and $\mathrm{HF}$, respectively), the resulting $\mathrm{Si}$ nanostructures will not be homogeneous in shape and size. Furthermore, when the reaction goes well, the reduced sample consists of $64.1 \mathrm{vol} \%$ $\mathrm{MgO}, 34.9 \mathrm{vol} \% \mathrm{Si}^{\left[{ }^{[4]}\right]}$ We can thus assume that when the magnesia is removed, the volume porosity is extremely high, perhaps too high for meta atoms. Another point is that during the thermal treatment the $\mathrm{Si}$ particles are sintered together. The fusion of Si structures will have an effect on their optical resonance and makes it extremely difficult to process the $\mathrm{Si}$ into a material. Perhaps Si sintering could be avoided by vaporizing the metal with a laser instead of thermally heating 
the whole system. In any case, the metallothermic strategy currently seems better suited to $\mathrm{Si}$ applications other than metamaterials.

\subsection{Combined Pressure and Temperature}

Thermal decomposition of a Si precursor can occur under low, ambient or high pressure. Low pressure techniques employ a gas phase precursor, typically silane or tetrachlor osilane, and consist of plasma synthesis, chemical vapor deposition (CVD) and aerosol synthesis. Higher pressure methods include supercritical and molten salt synthesis. In both cases it is essential to carry out the synthesis in an inert atmosphere, due to the extreme reactivity of silanes and chlorosilanes towards water and oxygen.

\subsubsection{Low-Pressure Thermal Decomposition Methods 4.3.1.1. Plasma}

Gas phase thermal decomposition of a Si precursor is one of the best known routes to produce $\mathrm{Si}$ nanostructures. Plasma synthesis and aerosol synthesis are common tech niques for the gas phase production of freestanding $\mathrm{Si}$ particles. Typically, plasma synthesis produces small $\mathrm{Si}$ quantum dots by decomposing $\mathrm{SiH}_{4}$ in an Ar plasma. ${ }^{[50,51]}$ In some cases $\mathrm{SiCl}_{4}$ is used as a precursor instead of $\mathrm{SiH}_{4}$ in the plasma synthesis. Since the reactivity of $\mathrm{SiCl}_{4}$ is lower than the reactivity of $\mathrm{SiH}_{4}, \mathrm{H}_{2}$ must be added to the Ar plasma, to reduce the $\mathrm{SiCl}_{4}$ to $\mathrm{Si}$.

Owing to the nature of the experimental design, which is straddled with a short precursor residence time in the reactor and low precursor partial pressure ${ }^{[51]}$ it is hard to produce $\mathrm{Si}$ structures larger than $10 \mathrm{~nm}$. Typically, Si nanoparticles larger than $10 \mathrm{~nm}$ are polycrystalline or amorphous, with broad size distributions. Some control over size, size distribution and structure can be exerted by tuning the plasma properties (plasma power, plasma density). Bapat et al. observed the formation of cubic, single crystal $\mathrm{Si}$ nanoparticles produced by rotating in a high density plasma filament; the average particle size was $35 \mathrm{~nm}$, and the cubic crystals exhibited narrow size distribution. ${ }^{[52]}$ They reported that the temper ature reached is high enough to allow the complete sintering of small Si nuclei into large cubic crystals. The degree of crystallinity depends on the power input, where a higher degree of crystallinity occurs upon increasing the power which generates the plasma. ${ }^{[53]}$ These results show that it is technically possible, by engineering the plasma properties, to control the size and crystallinity of the produced $\mathrm{Si}$ nano particles. Nevertheless, currently there are no reports of the plasma synthesis of Si nanoparticles larger than $40 \mathrm{~nm}$. The difficulty producing relatively large and monodisperse $\mathrm{Si}$ crystals, along with low reaction yields make plasma synthesis currently unsuitable for the production of Si meta atoms.

\subsubsection{Aerosol}

In aerosol synthesis, a molecular precursor, most com monly silane, is decomposed by pyrolysis to produce solid $\mathrm{Si}$ clusters suspended in a flow of inert gas. The energy to induce the pyrolysis of the molecular precursor is provided either by resistive heating of the reactor walls, ${ }^{[54]}$ or by irradiation with a $\mathrm{CO}_{2}$ laser beam. ${ }^{[55]}$

Thermal decomposition of silane typically occurs at temperatures between 900 and $1300^{\circ} \mathrm{C}$ and pressures between 25 and $800 \mathrm{mBar} .^{[54,56,57]}$ The temperature, the total pressure in the reactor and the silane partial pressure are fundamental parameters, having a considerable effect on the size, size dispersion, crystallinity ${ }^{[58]}$ and even the shape of the produced particles. ${ }^{[59]}$ Ostraat et al. observed a size increase from 6 $7 \mathrm{~nm}$ to $40 \mathrm{~nm}$ upon increasing the silane concentration from $10 \mathrm{ppb}$ to $3300 \mathrm{ppb} .{ }^{[56]}$ Körmer et al. ${ }^{[58]}$ investigated the effect of silane partial pressure (i.e. the concentration) on the particle size: they observed an increase in the average size of Si particles from 25 to $40 \mathrm{~nm}$ by decreasing silane pressure from $1 \mathrm{mbar}$ to $0.5 \mathrm{mbar}$. The discrepancy in these two results arises from the particle growth mechanism, which proceeds through homogenous growth in the first case and heteroge neous growth in the latter. Körmer et al. also studied how individual experimental conditions influence the size and crystallinity of the Si particles. They were able to design octahedral Si crystals with a $100 \mathrm{~nm}$ edge instead of spheres by lowering the silane partial pressure (1 mBar in $100 \mathrm{mBar}$ of Ar instead of $0.5 \mathrm{mBar}$ in $25 \mathrm{mBar}$ of Ar). ${ }^{[59]}$ Adjusting the total and silane partial pressure, heterogeneous growth can be favored over homogeneous growth, producing large, mono disperse and crystalline particles.

The continuous flow aerosol reactor design is another fundamental parameter: the synthesis conditions (e.g. tem perature, partial pressure) can be varied along the length of the reactor, to spatially separate the different reaction mechanisms. Alam and Flagan developed a continuous flow aerosol reactor consisting of two different zones, respectively called the seed reactor and the primary reactor. ${ }^{[60]}$ In the seed reactor, small $\mathrm{Si}$ nuclei were produced by the thermal decomposition of silane $\left(\mathrm{SiH}_{4}\right)$. In the primary reactor heterogeneous growth of micrometer sized particles was promoted, by decreasing the number concentration of the seed particles.

In the aerosol continuous flow reactor the size, size dispersion, particle shape and surface chemistry are con trolled by tuning the synthesis conditions and through reactor design. Considering these characteristics, aerosol synthesis could be applied to produce $\mathrm{Si}$ meta atoms with the required size $(75200 \mathrm{~nm})$, narrow size dispersion, purity and density. The powders obtained from aerosols should be easy to further process into a material, the only concern being the low production rate (few g per $\mathrm{h}$ ) due to particle deposition on the reactor walls. ${ }^{[58]}$

\subsubsection{Chemical Vapor Deposition}

Shirai et al. reported the synthesis of Si nanocrystals via radio frequency plasma enhanced chemical vapor deposition techniques using a mixture of $\mathrm{SiCl}_{4}, \mathrm{H}_{2}$, and $\mathrm{SiH}_{2} \mathrm{Cl}_{2} \cdot{ }^{[61]}$ Many parameters such as radio frequency power, pressure and deposition temperature influence the size and density of $\mathrm{Si}$ dots. For example at $150^{\circ} \mathrm{C}$, growth was favored over 
nucleation which led to large particles and a narrower size distribution $(2030 \mathrm{~nm})$. At $250^{\circ} \mathrm{C}$ sizes between $535 \mathrm{~nm}$ were obtained, centered around $20 \mathrm{~nm}$. Using silane as a precursor, $\mathrm{Si}$ nanowires were synthesized by chemical vapor deposition at $650^{\circ} \mathrm{C}$. Depending on the carrier gas, different $\mathrm{Si}$ nanowire diameters and lengths were obtained. Short and thick nanowires were reached using $\mathrm{N}_{2}$ as a carrier gas ${ }^{[62]}$ Using a mixture of $\mathrm{N}_{2}$ and $\mathrm{H}_{2}$ yielded longer and thinner nanowires.

Besides long nanowires, the CVD technique also permits the production of spherical Si particles through the decom position of disilane gas at temperatures above $400^{\circ} \mathrm{C}^{[63,64]}$ These large particles showed a strong light scattering for near infrared wavelengths. Fenollosa et al. prepared large and polydisperse $\mathrm{Si}$ spheres with sizes ranging from 0.5 to $5 \mu \mathrm{m} .{ }^{[63]}$ The as synthesized spheres were porous and amorphous, but were annealed at $800^{\circ} \mathrm{C}$ to convert the particles into polycrystalline $\mathrm{Si}$. Transmittance measurements of spheres with different sizes were performed: the average diameters of these spheres were $1.8 \pm 0.5 \mu \mathrm{m}$ and $1.5 \pm 0.4 \mu \mathrm{m}$. Both structures exhibit transmittance at wavelengths between 2.5 and $10 \mu \mathrm{m}$. The transmittance was more intense for the larger spheres.

With chemical vapor deposition, different shapes and sizes have been obtained. For metamaterials, this technique could be promising because large Si particles can be produced (sub micrometer and micrometer sizes). These particles show Mie scattering in the near IR. However, this system is not ideal because the size distribution cannot be controlled and the as synthesized particles are often amorphous. For these reasons, no visible scattering was observed using this tech nique.

\subsubsection{High-Pressure Thermal Decomposition and Thermal Reduction Methods 4.3.2.1. Supercritical Route}

A fluid becomes supercritical when it is heated and pressurized above its critical point. The thermophysical properties of a supercritical fluid, such as density and viscosity, are intermediate between the properties of its liquid phase and its gas phase. By varying the temperature and pressure in the supercritical domain these properties change continuously from gas like to liquid like, without the abrupt discontinuity typical of phase changes. Supercritical fluids are powerful reaction media for the synthesis of nanomaterials; they combine high mobility of the reactive species, characteristic of the gas phase, with the possibility to solvate precursors in concentrations comparable to solution chemistry routes. The combination of these two effects increases the reaction kinetics and allows the efficient syn thesis of nanomaterials. ${ }^{[6569]}$

Supercritical synthesis has been applied to the production of $\mathrm{Si}$ nano and microparticles. ${ }^{[35,7073]}$ As for gas phase synthesis, supercritical synthesis involves the thermal decom position of a Si molecular precursor. Working at high pressure helps reach the high temperatures necessary for the pyrolysis while simultaneously keeping the molecular precursor sol vated. This peculiarity places supercritical synthesis at the midpoint between solution chemistry and gas phase thermal decomposition.

Supercritical synthesis is performed either in batch or in a continuously fed reactor, where a solution containing the precursor is heated to the desired temperature (between 380 and $500^{\circ} \mathrm{C}$ ). $\mathrm{Si}$ particles have been synthesized either by chemical precursor reduction or by thermal decomposition.

Heath produced monocrystalline $\mathrm{Si}$ particles by tetra chlorosilane reduction with sodium in a tightly closed batch reactor. ${ }^{[73]}$ The reaction was performed at $385^{\circ} \mathrm{C}$, over several days (from 3 to 7 days), generating large and monocrystalline particles, with sizes between $5 \mathrm{~nm}$ and $3 \mu \mathrm{m}$. It is quite likely that nanoparticles a few nanometers in size were initially produced, which then agglomerated into larger crystals. The possibility to produce large and crystalline particles would make this route promising for the design of $\mathrm{Si}$ meta atoms, however there are several important drawbacks: a large size dispersion, poor yield and most notably the highly dangerous synthetic conditions.

$\mathrm{Si}$ nanoparticles have been prepared through the thermal decomposition of diphenylsilane in a supercritical mixture of $\mathrm{n}$ hexane and octanol ${ }^{[70]}$ and from trisilane in supercritical $\mathrm{n}$ hexane. ${ }^{[35,71,72]}$ The synthesis with diphenylsilane produces very small, crystalline $\mathrm{Si}$ quantum dots $(14 \mathrm{~nm})$, while thermal decomposition of trisilane yields large, amorphous Si beads (Figure 11). This large difference is mainly due to the difference in reactivity between the two precursors and the presence of additives that serve as capping ligands. The size of the beads depends on the initial concentration of trisilane, while their structure that is, bond order and the degree of hydrogenation depends on the reaction temperature and pressure. Harris and co workers observed that the size of $\mathrm{Si}$ spheres increased with increasing trisilane concentration. ${ }^{\text {[72] }}$ This may be due to diffusion limited growth, however the mechanism has not yet been studied in detail. Increasing the synthesis temperature from 380 to $450^{\circ} \mathrm{C}$ results in a higher bond order and reduced hydrogenation.

Shi et al. ${ }^{[35]}$ produced and characterized amorphous $\mathrm{Si}$ particles active in the infrared via solvothermal synthesis. Post synthetic thermal annealing reduced the porosity and the degree of hydrogenation of these materials. Accordingly, the refractive index increased as a function of the annealing temperature. Light transmittance measurements on single $\mathrm{Si}$ meta atoms before and after annealing confirm what was discussed in Section 3.2. The reduced porosity led to a redshift in the troughs in the transmission, corresponding to the magnetic and electric resonances.

Supercritical synthesis has so far provided one of the most promising routes to $\mathrm{Si}$ meta atoms, yielding the production of large Si particles with the possibility to control the particles' size and structure. ${ }^{[72]}$ In particular, the reduction of $\mathrm{SiCl}_{4}$ with $\mathrm{Na}^{[73]}$ and the thermal decomposition of $\mathrm{Si}_{3} \mathrm{H}_{8}{ }^{[35]}$ were the two techniques that seemed the most applicable for the synthesis of meta atoms. Both techniques fulfill the size requisite, being able to produce particles up to the micrometer scale. However, in one case the particles were too polydisperse, and in the other the particles were amorphous and porous. Perhaps by combining the advantages of these tech niques, short reaction time, a highly reactive precursor and 

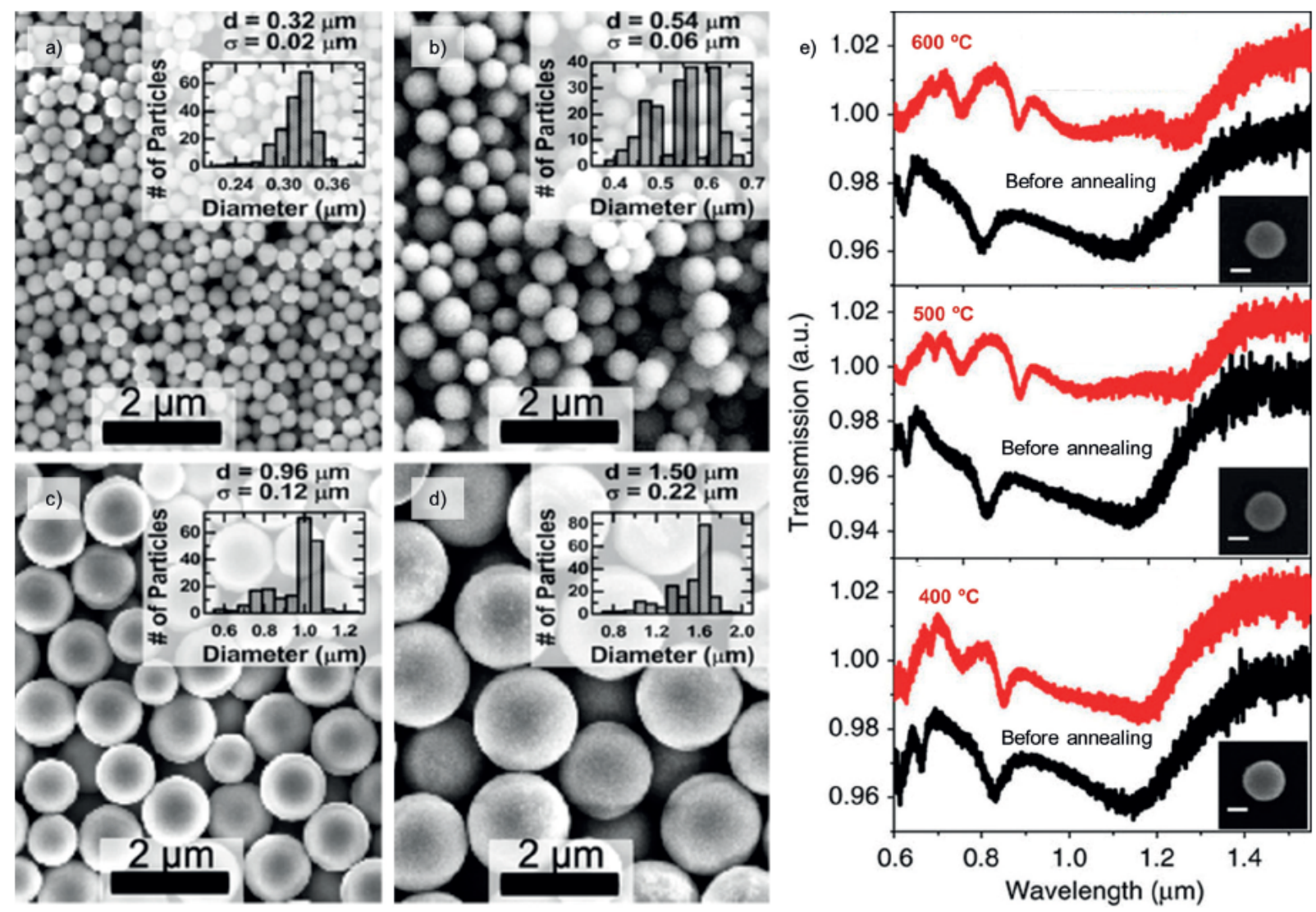

Figure 11. SEM images of the amorphous Si spheres obtained using a) $20, b) 60$, c) 100 , and d) $300 \mu \mathrm{L}$ of trisilane in $5.8 \mathrm{~mL}$ of $\mathrm{n}$ hexane. e) Transmission spectra of three meta atoms before (black) and after annealing (red) at 600,500 , and $400^{\circ} \mathrm{C}$. Insets: SEM images of the Si particles corresponding to the transmission spectra. The scales bars represent $200 \mathrm{~nm}$. Reproduced with permission from Refs. [35, 72].

a hydrogen free synthesis, nearly ideal particles could be produced.

\subsubsection{Molten Salts}

Common $\mathrm{Si}$ precursors decompose at relatively high temperatures, for instance thermal decomposition of $\mathrm{SiCl}_{4}$ begins at $800^{\circ} \mathrm{C}$. This temperature is much higher than the thermal decomposition temperature of aprotic organic sol vents. Thus it is natural to combine high pressure and temperature to decompose $\mathrm{Si}$ precursors and to provide the energy necessary to grow larger particles through either heterogeneous or homogeneous growth.

Molten salts can be used as a solvent from between 300 $1000^{\circ} \mathrm{C}$. Molten salts are inexpensive and scalable, so they present a marketable alternative to common $\mathrm{Si}$ synthetic methods. Both the reduction of $\mathrm{SiO}_{2}$ and the reduction of $\mathrm{Si}$ precursors to $\mathrm{Si}$ have been performed in molten salts. An assortment of halide salts have been used: $\mathrm{LiCl} / \mathrm{KCl}, \mathrm{ZnCl}_{2}$, $\mathrm{MgCl}_{2} / \mathrm{NaCl}$ and $\mathrm{AlCl}_{3}$. These halide salts scavenge heat to prevent exothermic runaway reactions and side reactions, such as the formation of $\mathrm{Mg}_{2} \mathrm{Si}^{\left[{ }^{[74]}\right.} \mathrm{The} \mathrm{ZnCl}_{2}{ }^{[75]}$ and $\mathrm{AlCl}_{3}{ }^{[76,77]}$ salts participate directly as reagents in the reduction through the following reactions [Eq. (2) (4)]:

$\mathrm{Mg}_{2} \mathrm{Si}+2 \mathrm{ZnCl}_{2} \rightarrow \mathrm{Si}+2 \mathrm{MgCl}_{2}+2 \mathrm{Zn}$
$4 \mathrm{Al}+3 \mathrm{SiO}_{2}+2 \mathrm{AlCl}_{3} \rightarrow 3 \mathrm{Si}+6 \mathrm{AlOCl}$

$2 \mathrm{Mg}+\mathrm{SiCl}_{4}+4 \mathrm{AlCl}_{3} \rightarrow \mathrm{Si}+2 \mathrm{MgAl}_{2} \mathrm{Cl}_{8}$

The zinc chloride and aluminum chloride lower the temper ature of reaction significantly; the reduction occurs between $200300^{\circ} \mathrm{C}$. When either $\mathrm{Al}$ or $\mathrm{Mg}$ metal is used without the metal chloride, the necessary $\mathrm{SiO}_{2}$ reduction temperature is above $660^{[76]}$ and $600^{\circ} \mathrm{C},{ }^{[78]}$ respectively.

$\mathrm{MgCl}_{2}$ is a relatively good solvent for $\mathrm{Mg}$ metal, facilitat ing the reduction and leading to larger $\mathrm{Si}$ nanoparticle diameters than in other halide salts. ${ }^{[78]} \mathrm{SiO}_{2}$ reduction in molten salts is not exactly the same mechanism as that of the metallothermic reduction discussed in Section 4.2. In molten salts, the metal is ionized and the electrons are solvated.

In all of the molten salt examples cited, the nanoparticles are ill formed and polydisperse in size. There is one exception where roughly spherical, hollow particles are generated by the Kirkendall effect. ${ }^{[74]}$ Although this technique is promising due to its environmentally friendly, economical and scalable process, and because it generates highly crystalline samples, a way to achieve spherical particles of controllable size must be found in order to make Si meta atoms using a molten salt route.

The bottom up techniques here presented have in common the use of high temperatures (from 400 to 
$1300^{\circ} \mathrm{C}$ ), which produce large $\mathrm{Si}$ particles, from several tens to thousands of $\mathrm{nm}$. This range of sizes is not typically accessible to traditional solution chemistry techniques. Aerosol syn thesis and supercritical thermal decomposition are particu larly promising for $\mathrm{Si}$ meta atoms production, as they provide particles that are monodisperse in size and shape and crystalline (in the case of aerosol).

\subsection{Solvents}

When choosing a solvent for $\mathrm{Si}$ synthesis, the solvent needs to be air free and water free to avoid the formation of silica. All terminal alcohols must also be avoided as $\mathrm{Si}$ precursors readily form alkoxysilanes upon contact. Solvent consideration does not stop with these factors. The solvent has an effect on the solubility of the Si precursor, the reducing agent and the intermediate species. The solvent can stabilize or destabilize the growing $\mathrm{Si}$ structures. If surfactants are present in the solution, their capacity to form micelles and their interactions with the Si precursors and the nanoparticles are determined by the properties of the solvent. Thus the solvent affects nucleation and growth processes, influences the form and even the crystallinity of the $\mathrm{Si}$ nanoparticles produced.

Despite the important role of the solvent on $\mathrm{Si}$ nano structure formation, studies of its effects have been largely neglected. Two studies report the synthesis of crystalline $\mathrm{Si}$ in glycol ethers, where other solvents yield amorphous particles. Neiner et al. reported the production of $4.91 \pm 1.23 \mathrm{~nm}$ crystalline $\mathrm{Si}$ particles through the reaction of $\mathrm{NaSi}$ with ammonium bromide using glyme at $80^{\circ} \mathrm{C}^{[79]}$ When instead dioctyl ether was used at $260^{\circ} \mathrm{C}$, the reaction of these same precursors generated amorphous $\mathrm{Si}, 3.85 \pm 1.03 \mathrm{~nm}$ in diam eter. Normally higher temperatures are more likely to produce crystalline nanoparticles, so we attribute the differ ence in crystallization to a solvent effect. Another study reacted $\mathrm{KSi}$ with $\mathrm{SiCl}_{4}$ in either $\mathrm{THF}$, glyme or diglyme. When diglyme and glyme were used, mostly crystalline particles were obtained, while in THF amorphous $\mathrm{Si}$ was produced. ${ }^{[80]}$ Glycol ethers are known to complex cations. ${ }^{[81]}$ We can speculate that glycol ethers may also stabilize the $\mathrm{Si}$ nano particle surface. If this is the case, ligand desorption from the surface during nanoparticle growth induces strain. When the atoms in a nanoparticle relax, they take the energetically more favorable crystalline state. ${ }^{[82]}$

Solvents affect not only the crystallinity, but also the size of Si particles. Baldwin et al. obtained nanocrystalline Si with different shapes: spherical ${ }^{[83]}$ and tetrahedral. ${ }^{[84]}$ Five nm Si particles were obtained in glyme, while a combination of THF and glyme produced $\mathrm{Si}$ nanocrystals ranging in size between 40 and $80 \mathrm{~nm}$. In the latter case, the (111) plane was predominant in tetrahedral crystals due to its lower surface energy which led to preferential growth. ${ }^{[85]}$

Solvent can have a drastic effect on yield. Chen et al. showed that the reduction of silicon chloride with $\mathrm{Mg}$ in glyme produced amorphous $\mathrm{Si}^{\left[{ }^{[86}\right.}$ Using THF, a low yield of $\mathrm{Si}$ nanoparticles was obtained, while no $\mathrm{Si}$ nanoparticles could be formed in toluene or anisole. In another example, mono phenylsilane was thermally decomposed to $\mathrm{Si}$ nanowires at $500^{\circ} \mathrm{C}$ under pressure in either benzene, toluene or hexane, where other conditions were unchanged. ${ }^{[87]}$ The Si nanowire yield was highly dependent on the nature of the solvent. In the case of hexane, only $1.4 \mathrm{wt} \%$ of the precursor was reduced to $\mathrm{Si}$ nanowires. In toluene the yield was $38.4 \mathrm{wt} \%$ and in benzene it was $63.0 \mathrm{wt} \%$. Moreover, the degree of $\mathrm{Si}$ crystallinity was highest when benzene was used as a solvent. They proposed that the solvent is involved in stabilizing the transition state during the precursor decomposition.

Solvents have a central role in $\mathrm{Si}$ nanoparticle yield, crystallinity and size. It is well possible that a Si analogue to the Stöber reaction could be discovered by finding a pair of miscible solvents that favor $\mathrm{Si}$ nanoparticle growth while maintaining monodispersity. One solvent should have poor interactions with the $\mathrm{Si}$, encouraging aggregation, while the other solvent should solubilize the $\mathrm{Si}$ precursors and have a good interaction with the $\mathrm{Si}$ nanoparticle surface, to ensure that the Si nanoparticles remain suspended in solution. The reducing agent must also be miscible with the solvents. Further study into solvent effects will allow scientists to intelligently target solvent pairs.

\subsection{Reducing Agents}

In the solution synthesis of Si nanoparticles, the reducing agent has a large influence on the particle size and dispersity. Common chemical reductants include $\mathrm{H}_{2}$ gas, metals, such as $\mathrm{Na}, \mathrm{K}, \mathrm{Mg}$ and $\mathrm{Zn}$, organic salts, such as sodium napthalenide and its derivatives, and hydrides, such as sodium borohydride and lithium aluminum hydride. The strength of chemical reductants can be classified in order from weakest to strongest: $\mathrm{H}_{2}$ gas $<$ metals $<$ organic salts $<$ hydrides. This trend has a direct impact on the size of resulting $\mathrm{Si}$ nano particles. It is well known that a strong reducing agent favors fast nucleation, consuming most of the precursor. ${ }^{[85]}$ Thus, small particles are typically obtained by strong reductants. A weaker reductant generates less nuclei due to the slower rate of reduction. The remaining $\mathrm{Si}$ precursor will more likely be used to grow larger particles in this case.

Sodium naphthalide ${ }^{[88]}$ sodium cyclopentadienide ${ }^{[89]}$ and potassium naphthalide ${ }^{[00]}$ are used to reduce $\mathrm{SiCl}_{4}$ to synthe size $\mathrm{Si}$ nanocrystals at ambient temperature. The reduction of Si salts occurs by one electron transfer from the radical anion. The size of Si obtained using this kind of reductant generally ranges between 3 and $80 \mathrm{~nm}$ depending on the reducing agent/Si precursor ratio and the solvent nature.

Powerful reducing agents such as hydrides have been largely used to synthesize $\mathrm{Si}$ quantum dots. Silicon particles with narrow size distribution are usually obtained with this kind of reductant combined with the inverse micelles method. The most popular hydrides used are $\mathrm{Li}\left(\mathrm{AlH}_{4}\right)$ and $\mathrm{Na}\left(\mathrm{BH}_{4}\right)$. The Pauling electronegativity of aluminum is 1.61 while that of borium is 2.04. Since $\mathrm{Al}$ is less electronegative than $\mathrm{B}, \mathrm{Al}$ will be more able to release an electron in favor of hydrogen to form a hydride $\left(\mathrm{H}^{-}\right)$than $\mathrm{B}$ and in turn the $\mathrm{Al} \mathrm{H}$ bond will be weaker than that of $\mathrm{B} \mathrm{H}$. Thus $\mathrm{LiAlH}_{4}$ is much more reactive than $\mathrm{NaBH}_{4}$. Although these reducing agents pro 
duce monodisperse nanoparticle size distributions, the largest reported $\mathrm{Si}$ nanoparticles produced from hydrides are $10 \mathrm{~nm} \cdot{ }^{[91]}$

Larger nanoparticles can be obtained using $\mathrm{Mg}$ as a reducing agent. Chen et al. used $\mathrm{Mg}$ to prepare $\mathrm{Si}$ nano particles up to $50 \mathrm{~nm}$ in diameter. ${ }^{[86]}$ The experiment was carried out in glyme, which solvated the magnesium. Since magnesium is less reactive than sodium or potassium, this soft reductant increases the likelihood of obtaining larger nano particles, but only if an appropriate solvent is used.

To form a meta atom, it is clear that a mild reducing agent is needed to obtain a larger particle size. We must also note that the reducing agent should not pollute the $\mathrm{Si}$ nano structure. Metal reductants and organic salts reduce the $\mathrm{Si}$ precursor via electron transfer, creating pure Si under mild conditions. The hydride reductants contaminate the $\mathrm{Si}$ with hydrogen, which decreases the quality of the optical proper ties ${ }^{[35]}$ while producing small nanoparticles.

\subsection{Stabilizing Agents}

Stabilizing agents can be used to control the size and size dispersion of nanoparticles. Additionally they can be used to prevent particle agglomeration. In $\mathrm{Si}$ particle synthesis, surfactants have been used in the inverse micelles method. ${ }^{[92]}$ Inverse micelles occur when the concentration of a surfactant (which contains both hydrophilic and hydro phobic sections) exceeds the critical micelle concentration in a hydrophobic organic solvent. However, this method invar iably generates nanoparticles that are about the same size as the micelle core (typically several $\mathrm{nms}$ ).

Shirahata and co workers emphasized the effect of surfactants on monodispersity. ${ }^{[93]}$ They reported that in the presence of tetraoctyl ammonium bromide, a narrow dis persion of $\mathrm{Si}$ nanoparticles was reached at room temperature via the reduction of $\mathrm{SiCl}_{4}$ with $\mathrm{Na}$ naphthalenide. The mean size, estimated after removing the organic shell, was $3.4 \mathrm{~nm}$ $\pm 1.8 \mathrm{~nm}$. In the absence of tetraoctyl ammonium bromide, the size distribution was random with a mean size of $9.5 \mathrm{~nm}$ and a standard deviation of $5.6 \mathrm{~nm}$. Tilley et al. were able to obtain the most monodisperse and smallest $\mathrm{Si}$ nanocrystals $(1.8 \pm 0.2 \mathrm{~nm})$, by a room temperature reaction between a silicon tetrachloride precursor and $\mathrm{LiAlH}_{4}$, a hydrogen source, and using tetraoctyl ammonium bromide a as surfac tant. ${ }^{[94]}$ Caution: it is highly likely that during the reaction, the silicon halide is hydrogenated to make silane at room temperature. Such an experiment is highly dangerous and rigorous precautions must be taken to protect the reaction from air and to be prepared for fire in case of an accidental leak.

Ligands usually permit high monodispersity but also limit $\mathrm{Si}$ particle growth. Perhaps using ligands as stabilizing agents rather than as micellar templates will allow the production of larger, monodisperse $\mathrm{Si}$ nanoparticles. For this to be the case, the organic molecules should have a relatively low affinity, adsorbing and desorbing from the surface and thus encourag ing a homogeneous nanoparticle growth.

\subsection{Relative Concentrations \\ 4.7.1. Precursor Concentration}

The precursor concentration affects the size and size distribution of $\mathrm{Si}$ particles. When the precursor's concentra tion exceeds a certain value, supersaturation occurs. Super saturation leads to the sudden consumption of the precursor and to the production of many small nuclei, that may coalesce into bigger particles by homogeneous growth. The concen tration required to have supersaturation depends on the type of chemical reaction (e.g. type of precursor, decomposition kinetics) and on the synthesis conditions. Working below the supersaturation limit produces few nuclei, that then may grow by heterogeneous growth. The effect of precursor concen tration has been deeply investigated in the case of aerosol synthesis (see Section 4.3). Körmer and co workers observed that a silane partial pressure inferior to $1 \mathrm{mbar}$ in $100 \mathrm{mbar}$ of Ar allowed the production of Si objects larger than $100 \mathrm{~nm}^{[58]}$ The concentration even seemed to affect the shape of the produced particles, probably due to the preferential growth of certain crystallographic planes. ${ }^{[59]}$ Pell et al. ${ }^{[71]}$ did a series of experiments with increasing precursor concentration under supercritical conditions. The particle size increased with increasing precursor concentration. This trend opposes that observed by Körmer et al. ${ }^{[59]}$ which can be explained by the fact that the saturation limit was surpassed and therefore particle growth occurred by coalescence.

\subsubsection{Reducing-Agent Concentration}

The concentration of reductant has a considerable effect on the particle size. Balci et al. reported that $\mathrm{Si}$ particle size changed as a function of the $\mathrm{Si}$ precursor/reducing agent ratio ${ }^{\left[{ }^{90]}\right.}$ The largest particle size obtained was $27 \pm 4.8 \mathrm{~nm}$ by $\mathrm{SiCl}_{4}$ reduction using potassium naphthalide. The increase of $\mathrm{SiCl}_{4} /$ potassium naphthalide ratio from 0.224 to 0.289 permits a ten fold increase (respectively from $3.1 \pm 0.6 \mathrm{~nm}$ to $27 \pm$ $4.8 \mathrm{~nm}$ ) in the size of Si nanoparticles. A fast nucleation, as explained by the LaMer mechanism, due to a high concen tration of the potassium naphthalide increased the number of nuclei and hence small, crystalline Si particles were formed. A lower concentration of potassium naphthalide favored the growth of larger $\mathrm{Si}$ particles. The same trend was observed by Zou et al., who varied the ratio of $\mathrm{SiCl}_{4} /$ sodium naphthalide concentration. ${ }^{[95]}$ A ratio of 0.30 gave a particle diameter of $8.85 \pm 1.6 \mathrm{~nm}$, where a ratio of 0.27 yielded nanoparticles of $3.28 \mathrm{~nm}$

\subsection{Particle Growth}

Small crystalline $\mathrm{Si}$ nanoparticles can be coalesced into larger particles through oriented attachment. ${ }^{[85]}$ In Ostwald ripening, the growth of large nanoparticles at the expense of small nanoparticles, is not likely to occur. In this mechanism, small nanoparticles redissolve to provide precursor feed for the larger nanoparticles. However, $\mathrm{Si}$ cations cannot be appropriately complexed by the solvent and thus are too unstable to redissolve. However, small crystalline nanopar 
ticles can orient themselves so that they have a common crystallographic alignment and then coalesce. ${ }^{[96]}$ The forces promoting coalescence include Coulombic forces and van der Waals interactions.

\section{Crystallization Methods}

The position and intensity of visible light scattering depend on the degree of crystallinity and the size of the $\mathrm{Si}$ particles. In general, the degree of crystallization is poorly characterized, but some carefully conducted studies show their relationship. Raman spectroscopy can be used to quantify the crystallinity of the sample. ${ }^{[97]}$ Amorphous $\mathrm{Si}$ appears as a broad Raman peak centered around $480 \mathrm{~cm}^{-1}$. A purely crystalline bulk Si sample shows sharp Raman peaks centered at 520 and $939 \mathrm{~cm}^{-1}$. The size of Si crystallites can be measured using the full width at half maximum. Dark field optical images are typically taken of crystalline $\mathrm{Si}$, as the emitted color corresponds to the Si particle size and its degree of crystallinity (see Figure 5).

In this Section, two different techniques to produce crystalline Si particles will be discussed: thermal and laser induced crystallization. The major challenge is to obtain a high degree of crystallinity without sintering the particles or introducing a large quantity of porosity. If the particles sinter, their optical properties will be equivalent to bulk $\mathrm{Si}$ and it will be impossible to process the particles into a homogeneous material. When these particles are post synthetically crystal lized they become highly porous. ${ }^{[71]}$ The porosity stems from the following reason: amorphous materials occupy more volume than their crystalline counterparts. It is currently impossible to ensure homogeneous contraction during $\mathrm{Si}$ crystallization. Often $\mathrm{Si}$ porosity has not been characterized in literature reports, thus we cannot draw conclusions about which crystallization method generates the densest materials. But in general, slower crystallization provides more time for contraction and thus generates less porosity.

\subsection{Thermal Crystallization Methods}

Silicon normally requires temperatures of up to $800^{\circ} \mathrm{C}$ at ambient pressure to crystallize. It is possible to calcine under an inert atmosphere to crystallize, but at such a high temper ature, $\mathrm{Si}$ nanostructures sinter together. The extent of sintering and the risk of particle deformation increase as a function of temperature. ${ }^{[98]}$ Particle agglomeration hinders the assembly of particles into a homogeneous material. One solution is to use lower calcination temperatures and to catalyze crystallization with a devitrifying agent. ${ }^{[99]}$ This will minimize sintering. The small contact points between par ticles can be dissolved by first oxidizing the outer shell of the $\mathrm{Si}$ particles with air. The thickness of the silica shell can be increased by mildly heating the particles. Then the $\mathrm{SiO}_{2}$ shell can be etched with $\mathrm{HF}$ to liberate the $\mathrm{Si}$ particles (Fig ure 12 a). Many elements have been reported to devitrify $\mathrm{Si}$ thin films at relatively low temperatures. ${ }^{[100]}$ Some elements, such as nickel, copper and palladium, form silicides and the act of forming a covalent bond between the $\mathrm{Si}$ and a metal can catalyze crystallization. Others, such as $\mathrm{Al}, \mathrm{Sb}$, and $\mathrm{Au}$, do not form silicides. These additives diffuse from one interstitial site to another within the $\mathrm{Si}$ glass. Cation diffusion through the $\mathrm{Si}$ framework generates local stress, as $\mathrm{Si} \mathrm{Si}$ bonds are stretched to allow the cation to pass from one interstitial vacancy to another. These $\mathrm{Si}$ atoms may crystallize upon relaxation. If the cation is too small, for example, lithium, it behaves as a melting agent, catalyzing the crystallization at the expense of structural deformation. ${ }^{[101]}$ Under some conditions, the cations that form silicides may instead crystallize through interstitial diffusion producing pure crystalline $\mathrm{Si}^{\left[{ }^{[102]}\right.}$ The concentration of the devitrifying agent must also be con trolled, typically catalytic quantities of approximately $1 \mathrm{~mol} \%$ are required. ${ }^{[103]}$ If concentration is too high, interstitial diffusion occurs less because too many sites are occupied, blocking movement. If concentration is too low, crystallization does not occur. For $\mathrm{Si}$ the best devitrifying agents currently known are $\mathrm{Al}$ and $\mathrm{Au}$.

A previous study of amorphous $\mathrm{SiO}_{2}$ crystallization to quartz shows that devitrifying agents increase in strength from the top of the column to the bottom of the column of the periodic table. ${ }^{[101]}$ Knaepen reports the same tendency, with the heavier elements in the column crystallizing $\mathrm{Si}$ at lower temperatures (Figure $12 \mathrm{~b}$ ). ${ }^{[100]}$ They report a large effect from $\mathrm{Al}^{3+}$, but did not test other elements in the group, thus it is possible that $\mathrm{Ga}$, In, and $\mathrm{Ti}$ may catalyze $\mathrm{Si}$ crystallization at temperatures lower than $275^{\circ} \mathrm{C}$.

Devitrifying agents have thus far been applied exclusively to Si thin films, but there is no reason that this technique could not be used to crystallize $\mathrm{Si}$ particles or other structures.

\subsection{Laser-Induced Crystallization}

Lasers have been used to crystallize Si since 1979, when a ruby laser was used to regenerate monocrystalline $\mathrm{Si}$ from an ion doped sample. ${ }^{[104]}$ Crystallization occurs through a thermal process as the radiation energy from the laser is transferred to the electrons, which then heat the Si lattice. ${ }^{[105]}$ The laser energy can be tuned, high energies quickly heat the sample and thus the required annealing time is short that is on the order of nanoseconds. ${ }^{[106]}$ Application of a single femto second laser pulse can crystallize amorphous $\mathrm{Si}^{\left[{ }^{[107]}\right.}$ Although crystallization time is short and laser induced crystallization can generate large crystal grains, only small areas are irradiated by a laser. Thus laser crystallization treats individ ual particles ${ }^{[33]}$ or small sections of a nanostructure. ${ }^{[108,109]}$ Thus, this is not a currently practical method for bulk material synthesis.

Many parameters must be considered to optimize the crystallization. A wavelength range between $740760 \mathrm{~nm}$ yields the highest quality of crystallization. ${ }^{[110]}$ Moreover, the environment can affect the crystallization; when a Si thin film was encased in a silica layer, the crystal orientation changed, impacting the electrical and optical response. ${ }^{[108]}$ The beam intensity, the exposure time and the temperature gradient all additionally play a role, as we will show in the following paragraphs. Moreover, samples can be crystallized 


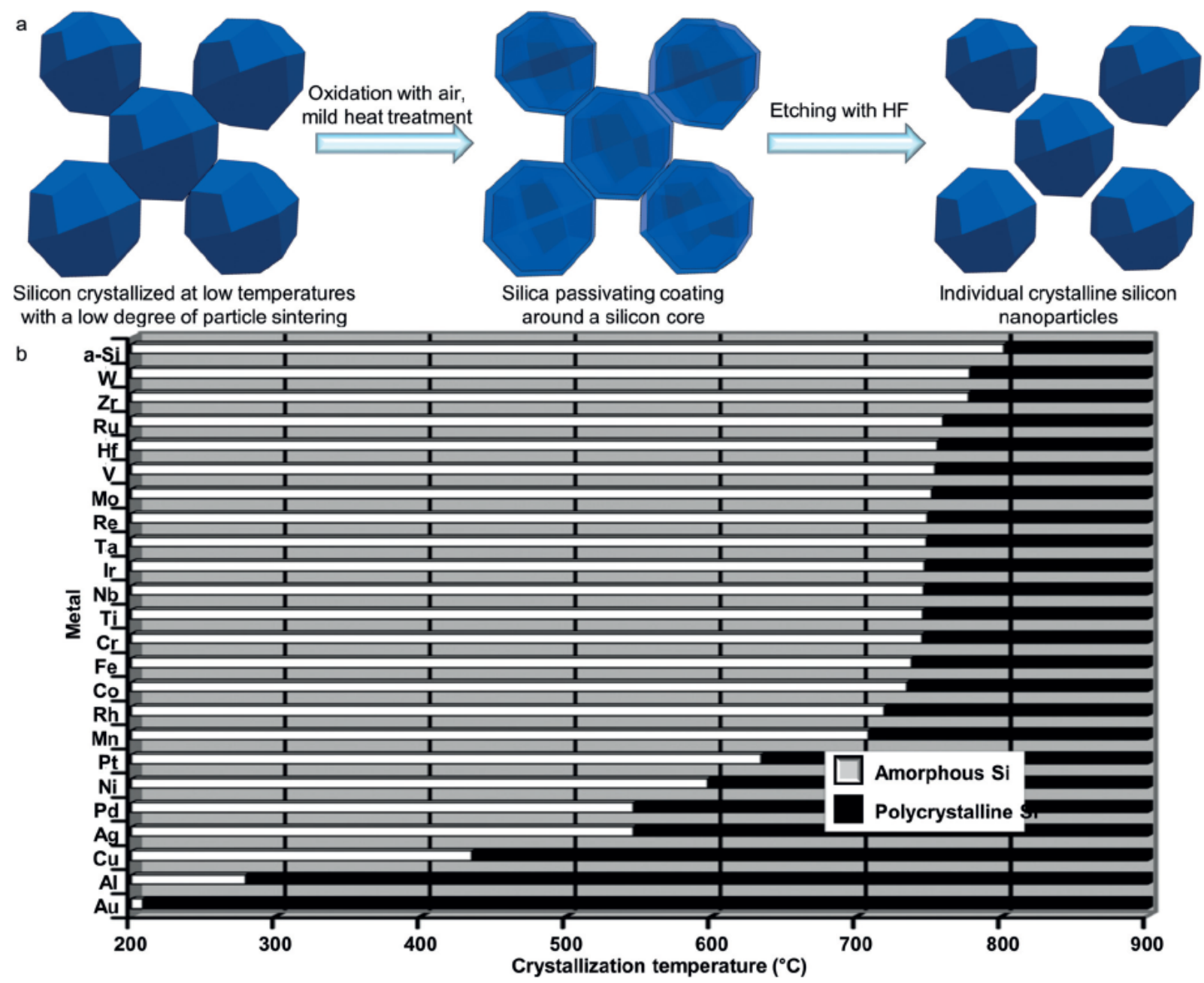

Figure 12. a) Lightly sintered $\mathrm{Si}$ objects can be subjected to surface oxidation and then $\mathrm{SiO}_{2}$ etching to liberate individual $\mathrm{Si}$ particles. b) The temperature of Si crystallization can be reduced using devitrifying agents, thereby minimizing particle sintering. Table reproduced with permission from Ref. [100].

and recrystallized using lasers, changing the degree of crystallinity, the crystal orientation and the grain size through multiple laser shots. ${ }^{[11]}$

Raman spectroscopy lasers have induced the crystalliza tion of amorphous $\mathrm{Si}$ nanomaterials. The laser heats the sample, typically crystallizing below the melting temperature and thus this crystallization method does not deform the nanostructure. ${ }^{[112]}$ Laser induced crystallization occurs via random nucleation and growth, which are dependent on both the temperature and the duration of the laser treatment (Figure 13). Higher laser power leads to more numerous nucleation events and thus smaller crystalline domains than lower laser power. Longer heat treatments provide the time needed for the crystal grains to grow in size. Laser induced crystallization and conventional calcination treatments both require the same temperatures.

A continuous wave argon laser operating at $488 \mathrm{~nm}$ has been used to crystallize a Si fiber core surrounded by a silica cladding. ${ }^{[109]}$ The temperature at the center of the laser spot is higher than at the edge, and the penetration depth of this laser technique is $490 \mathrm{~nm}$. A crack free Si nanostructure can be prepared when the temperature gradient is relatively low. A slow scanning speed $\left(<1 \mathrm{mms}^{-1}\right)$ has a larger temperature gradient than faster speeds. However, high speeds $\left(>4 \mathrm{~mm} \mathrm{~s}^{-1}\right)$ insufficiently distribute the energy over the irradiated area, leading to a higher content of amorphous material and polycrystallinity. Thus, the scan rate should be optimized to create monocrystalline Si structures. Similar Si fibers with silica cladding have been recrystallized to signifi cantly decrease the optical losses using a $28 \mathrm{~W} \mathrm{CO} 2$ laser, having a melt zone of $300500 \mu \mathrm{m} .{ }^{[113]}$ The thermal gradient applied less stress on the $\mathrm{Si}$ when a cladding was present as the temperature was transferred from the silica cladding to the core. Unfortunately, the recrystallization scan rate is 60 times slower than the drawing speed, so the two processes cannot currently be simultaneously applied.

The conclusion from studying the literature is that $\mathrm{Si}$ crystallization is still unsatisfactory in terms of material synthesis. Classical problems such as particle sintering and the generation of porosity plague Si crystallization. Laser induced crystallization produces denser $\mathrm{Si}$, but it is not easily scalable. Unfortunately, to date solvothermal methods have not been used to crystallize $\mathrm{Si}$, although solvothermal has been used for Si synthesis. ${ }^{[14,115]}$ Solvothermal synthesis has been shown to 

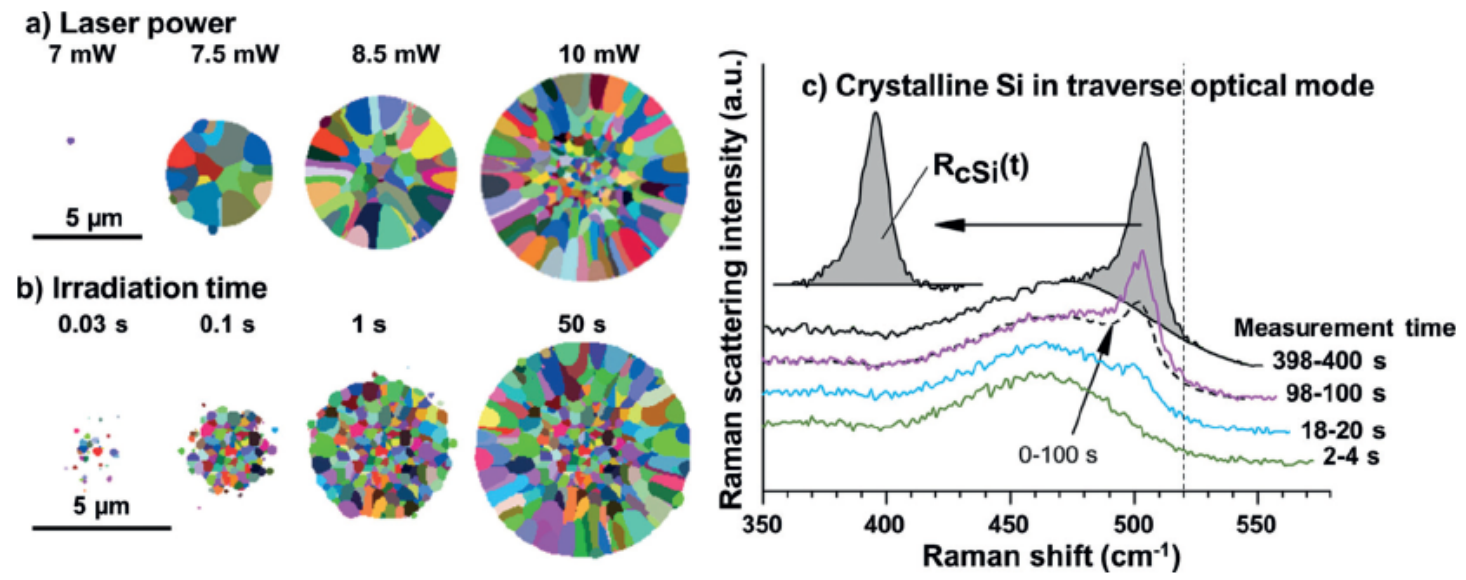

Figure 13. Numerical simulations show the degree of crystallization of initially amorphous Si. Each crystal grain is represented by a separate color. The degree of crystallization depends on the a) laser power ( $400 \mathrm{~s}$ of irradiation) and the b) irradiation time (applying a $10 \mathrm{~mW}$ laser). c) The progressive crystallization with time can be observed in the transverse optical mode of Raman spectroscopy. The dotted line shows the peak position for bulk crystalline Si. Images reproduced with permission from Ref. [112].

ripen other nanoparticle compositions, thus this is a method worth exploring. Moreover, some solution based synthetic methods generate crystalline Si directly. ${ }^{[79]}$ Currently we do not understand why sometimes amorphous and sometimes crystalline $\mathrm{Si}$ is obtained as a synthetic product, a question which begs exploration.

\section{Silicon Oxidation and Post-Synthesis Surface Modification}

Oxidation can affect the optical properties of $\mathrm{Si}$, yet surface oxidation is inevitable if air, water or oxygen is in contact with $\mathrm{Si}$. Si spheres form a passivating coating of $\mathrm{SiO}_{2}$, that then protects the $\mathrm{Si}$ from further oxidation, referred to as self limiting oxidation. Silica occupies more volume than $\mathrm{Si}$. As the surface oxidizes, compressive stress builds as more atoms try to occupy the original volume of space. When the energy gain upon $\mathrm{Si}$ oxidation is surpassed by the increase in strain energy, the passivating layer definitively stops growing unless the temperature changes. ${ }^{[37]}$ The Deal Grove model predicts that nanoparticles of smaller diameter will have a thinner oxide coating than larger nanoparticles because of the more significant volume expansion and thus the larger increase in compressive stress during the oxidation. ${ }^{[16]}$ However, others have reported the full oxidation of $\mathrm{Si}$ nanostructures of less than $10 \mathrm{~nm}$ in diameter. ${ }^{[117]}$ Silicon having a sub $10 \mathrm{~nm}$ diameter can deform upon oxidation. Compressive stress decreases with diameter and thus $\mathrm{Si}$ oxidation is favored. This is apt to be true for porous Si where walls are thin, though the concave shape of pores disfavors extensive oxidation because of the high compressive stress associated with this geometry. ${ }^{[118]}$ Large, nonporous $\mathrm{Si}$ (nano) particles exposed to air at room temperature should grow a passivating coating of approximately $2.1 \mathrm{~nm}$, which is not particularly disruptive to the optical scattering properties.

To preserve small or porous $\mathrm{Si}$ structures, and thus the optical properties, appropriate surface modification is required. Most synthetic protocols produce $\mathrm{Si}$ terminated with either hydrides, oxides or halogens. Thiols have also been used as capping ligands for $\mathrm{Si}$ nanocrystals, although the passivating layer is very susceptible to degradation by hydrolysis. ${ }^{[119]}$ The three major functionalization processes are:

1) Hydrosilylation which occurs between hydrogen termi nated $\mathrm{Si}(\mathrm{Si} \mathrm{H})$ and an unsaturated bond such as an alkene. This reaction is generally initiated by the presence of silyl radicals produced by the homolytic cleavage of the $\mathrm{Si} \mathrm{H}$ bond. Silyl radicals react with the terminal carbon carbon bond to induce a stable $\mathrm{Si} \mathrm{C}$ bond. For hydro silylation to be achieved, a metal, thermal treatment or light irradiation is needed to catalyze the reaction. ${ }^{[120]}$

2) Functionalization of halide terminated silicon $(\mathrm{Si} \mathrm{Cl})$ is mostly achieved via the Grignard reaction through the addition of $\mathrm{RMgBr}$ or $\mathrm{RLi}$ (when $\mathrm{R}$ is an alkyl group). These two functionalization processes are explained in great detail in several Reviews. $\left.{ }^{[121} 123\right]$

3) Silanization is generally a multi step reaction: first of all, the surface has to be modified with an alcohol and then treated with degassed $\mathrm{H}_{2} \mathrm{O}$ to decorate the surface with hydroxyl terminal groups. $\mathrm{OH}$ terminated nanoparticles then react with siloxane to form a core shell Si@silox ane. ${ }^{[88,124]}$

All $\mathrm{Si}$ synthesis reports highlight the importance of surface modification to protect the surface, however only a few articles actually report the oxidation behavior of functionalized $\mathrm{Si}$ nanoparticles upon contact with air. ${ }^{[88,125]}$ One of those reports shows the effect on photoluminescence of an aged silanized Si surface. Zou and Kauzlarich ${ }^{[88]}$ prepared silanized $\mathrm{Si}$ particles through a multi step function alization: starting with chloride terminated $\mathrm{Si}$, hydroxy terminated particles were obtained after the addition of methanol and then water. These particles were then mixed with chlorosilane precursors to form a siloxane shell. Si@si loxane core@shell particles provide a large enhancement of optical stability according to photoluminescence measure ments. Under an ambient atmosphere the chloride terminated 
Si lost their optical properties over 4 days, but the silanized particles maintained their luminescence over two months. ${ }^{[88]}$

A second report showed the effect of an aged hydro genated silicon surface on photoluminescence. ${ }^{[125]}$ An air free aging of 5 days showed a shift to shorter wavelengths for all particles. In air, the photoluminescence maxima decreased slightly the first day, then strongly from the second day to 13th day. This decrease was also accompanied with a shift to shorter wavelengths.

Surface functionalization concerns more than a barrier to oxidation, which may not even be problematic for the scattering properties of meta atoms. Surface chemistry can affect the assembly behavior of $\mathrm{Si}$ nanoparticles for the construction of 3D metamaterials and metasurfaces. For processing, colloidal stability and wettability must be consid ered. ${ }^{[126]}$ Functionalizing the silicon particles with either bulky polymers or charged molecules can prevent particle agglom eration in solution. Polymers give the particles steric stabili zation, allowing the colloids to stay suspended in solution longer, and thus giving more time to produce a homogenous material. Imparting charges to the surface can give the same effect. For wettability, it may be necessary to use a particular solvent. The surface of the silicon particles can be rendered hydrophilic to disperse the particles in water or short chain alcohols, $\left.{ }^{[127} 132\right]$ or hydrophobic ${ }^{[98,128,133]}$ to disperse them in organic solvents. By controlling the surface chemistry, homo geneous, close packed $\mathrm{Si}$ assemblies over a large surface can be produced. The surface chemistry can also improve the stability of colloidal assemblies. ${ }^{[134,135]}$

To summarize, the synthesis of $\mathrm{Si}$ particles has been attempted using a large variety of techniques, in gas, liquid and supercritical phase. Each of these has its own advantages and drawback for the pursuit of ideal Si meta atoms. We summarize the characteristics of thus obtained Si particles from the most promising techniques (Table 1).

\section{Conclusions and Outlook}

Theory has predicted and experiments have shown that ideal $\mathrm{Si}$ particles behave as Mie resonators at optical frequencies. An ideal Si nanoparticle is spherical, nonporous, crystalline, pure in composition (e.g. not polluted with hydrogen or carbon), monodisperse in size and form and between $75200 \mathrm{~nm}$ in diameter. An external oxide layer of a few nm is not a drawback and may even be an advantage for Si particle processing into a material. Any deviation from the ideal particle design affects the scattering efficiencies and the resonance frequencies. Thus chemists are not required to fill all conditions, for instance some amorphous character or some porosity could be tolerated. Even so, the experimental efforts made to date using bottom up synthesis methods have fallen short of the mark. Thus even though $\mathrm{Si}$ meta atoms have been produced by top down methods, no one has yet assembled $\mathrm{Si}$ meta atoms into a metamaterial. Theoretical opinions about the interest of $\mathrm{Si}$ meta atom assemblies are divided.

We have learned a lot about $\mathrm{Si}$ fabrication from the multitude of synthetic efforts, but these lessons are yet to be combined. A solution based method that avoids calcination seems necessary to produce spheres that can be processed into a material. Crystallization can occur via supercritical or solvothermal treatment, by adding devitrifying agents, such as $\mathrm{Au}$ or $\mathrm{Al}$, or via synthesis in particular solvents using certain

Table 1: Summary of the characteristics of Si particles produced through different synthetic routes.

\begin{tabular}{|c|c|c|c|c|c|c|c|}
\hline Method & Size & Dispersion & Morphology & Crystallinity & $\begin{array}{l}\text { Surface functio } \\
\text { nality }{ }^{[a]}\end{array}$ & Yield & Scalability \\
\hline Laser ablation & $70200 \mathrm{~nm}$ & High & Dense spheres & Amorphous & Oxide & Low & $\begin{array}{l}\text { Not scal } \\
\text { able }\end{array}$ \\
\hline $\begin{array}{l}\text { Supercritical fluids } \\
\text { (batch) }\end{array}$ & $\begin{array}{l}1000 \\
2000 \mathrm{~nm}\end{array}$ & Narrow & Porous spheres & Amorphous & Hydrides & $90 \%$ & Scalable \\
\hline Plasma assisted & $1040 \mathrm{~nm}$ & Narrow & Spheres or cubes & $\begin{array}{l}\text { Crystalline, Amor } \\
\text { phous }\end{array}$ & $\begin{array}{l}\text { Hydrides Chlor } \\
\text { ides }\end{array}$ & $\begin{array}{l}50 \\
80 \%\end{array}$ & $\begin{array}{l}\text { Not scal } \\
\text { able }\end{array}$ \\
\hline $\begin{array}{l}\text { Chemical vapor deposi } \\
\text { tion }\end{array}$ & $51000 \mathrm{~nm}$ & High & Spheres & $\begin{array}{l}\text { Partially crystal } \\
\text { line }\end{array}$ & $\begin{array}{l}\text { Hydroxides, } \\
\text { Hydrides }\end{array}$ & $\begin{array}{l}15 \\
70 \%\end{array}$ & Scalable \\
\hline Aerosol synthesis & $2100 \mathrm{~nm}$ & High & Spheres or octahedra & Crystalline & Hydrides & $\begin{array}{l}30 \\
70 \%\end{array}$ & Scalable \\
\hline $\begin{array}{l}\text { Metallothermic reduction } \\
\text { of } \mathrm{SiO}_{2}\end{array}$ & $\begin{array}{l}10 \\
2000 \mathrm{~nm}\end{array}$ & Low & $\begin{array}{l}\text { Irregular particles or spheres, } \\
\text { highly porous }\end{array}$ & Crystalline & Hydroxides & $\begin{array}{l}30 \\
50 \%\end{array}$ & Scalable \\
\hline Molten salts & $1040 \mathrm{~nm}$ & High & Irregular, dense & Crystalline & Hydroxides & $\begin{array}{l}10 \\
80 \%\end{array}$ & Scalable \\
\hline $\begin{array}{l}\text { High temperature reduc } \\
\text { tion }\end{array}$ & $280 \mathrm{~nm}$ & High & Spheres & $\begin{array}{l}\text { Crystalline, amor } \\
\text { phous }\end{array}$ & Alkanes, amines & $\begin{array}{l}30 \\
70 \%\end{array}$ & $\begin{array}{l}\text { Not scal } \\
\text { able }\end{array}$ \\
\hline
\end{tabular}

[a] Surface functionality refers to the as prepared particles before exposure to the ambient environment. 
precursors. It seems we need a gentle reductant that does not pollute the $\mathrm{Si}$ structure, such as $\mathrm{Mg}, \mathrm{Zn}$, or heat. The size of $\mathrm{Si}$ particles could be controllably increased via particle agglom eration or via seeded growth. Particle agglomeration could be encouraged by using a combination of a solvent and non solvent, as is the case in the Stöber synthesis of silica particles, or by using a combination of heat and pressure. Porosity can be minimized by crystallizing the nanoparticles from the beginning, rather than via post synthetic crystallization. There are a multitude of techniques that could produce such Si nanostructures, for instance solvothermal, supercrit ical, aerosol, and classical solution synthesis. Thus we are optimistic that chemists will synthesize nearly ideal $\mathrm{Si}$ meta atoms in the near future.

A well dispersed solution of monodisperse Si meta atoms could be assembled into tightly packed $2 \mathrm{D}$ and $3 \mathrm{D}$ materials using dip coating, spray coating, doctor blading, spin coating or micro evaporation via microfluidics. Designing non tightly packed arrays of Si particles through self assembly is another major challenge reserved for another Review. ${ }^{[126]}$

We can speculate on the possible advantages for society upon obtaining all dielectric based metamaterials. Polariza tion beam splitters should be possible by controlling the lattice spacing and thus the coupling strength between $\mathrm{Si}$ particles ${ }^{[136]}$ Silicon metasurfaces could also be used to convert circularly polarized light into linear polarization. Materials with negligible reflection, that is total transmission, should be achievable. ${ }^{[19]}$ The reverse should also be attainable by changing the thickness and arrangement of the Si meta atoms: negligible transmission. Such materials may one day be found in (bio)sensors, optical computing, total reflective coatings, and in total absorption coatings for photovoltaic devices.

\section{Acknowledgements}

M.L.D.M., S.S., and G.L.D. were supported by the LabEx AMADEus (ANR 10 LABX 42) in the framework of IdEx Bordeaux (ANR 10 IDEX 03 02), that is, the Investisse ments d'Avenir program of the French government managed by the Agence Nationale de la Recherche. B.A.K. acknowl edges funding by the Robert A. Welch Foundation (grant no. F 1464).

\section{Conflict of interest}

The authors declare no conflict of interest.

How to cite: Angew. Chem. Int. Ed. 2018, 57, 44784498 Angew. Chem. 2018, 130, 45684589

[1] C. Rockstuhl, C. Menzel, S. Mühlig, J. Petschulat, C. Helgert, C. Etrich, A. Chipouline, T. Pertsch, F. Lederer, Phys. Rev. B 2011, $83,245119$.

[2] D. R. Smith, W. J. Padilla, D. C. Vier, S. C. Nemat Nasser, S. Schultz, Phys. Rev. Lett. 2000, 84, 4184.

[3] R. A. Shelby, D. R. Smith, S. Schultz, Science 2001, 77, 292.
[4] D. Schurig, J. J. Mock, B. J. Justic, S. A. Cummer, J. B. Pendry, A. F. Starr, D. R. Smith, Science 2006, 314, 977.

[5] C. M. Soukoulis, M. Wegener, Nat. Photonics 2011, 5, 523.

[6] A. N. Grigorenko, A. K. Geim, H. F. Gleeson, Y. Zhang, A. A. Firsov, I. Y. Khrushchev, J. Petrovic, Nature 2005, 438, 335.

[7] S. Linden, C. Enkrich, M. Wegener, J. Zhou, T. Koschny, C. M. Soukoulis, Science 2004, 306, 1351.

[8] J. Zhou, L. Zhang, G. Tuttle, T. Koschny, C. M. Soukoulis, Phys. Rev. B 2006, 73, 041101.

[9] G. Dolling, M. Wegener, C. M. Soukoulis, S. Linden, Opt. Lett. 2007, 32, 53.

[10] T. Xu, A. Agrawal, M. Abashin, K. J. Chau, H. J. Lezec, Nature 2013, 497, 470.

[11] S. Mühlig, A. Cunningham, S. Scheeler, C. Pacholski, T. Bürgi, C. Rockstuhl, F. Lederer, ACS Nano 2011, 5, 6586.

[12] S. N. Sheikoleslami, H. Alaeian, A. L. Koh, J. A. Dionne, Nano Lett. 2013, 13, 4137.

[13] V. Ponsinet, P. Barois, S. M. Gali, P. Richetti, J. B. Salmon, A. Vallecchi, M. Albani, A. Le Beulze, S. Gomez Graña, Phys. Rev. B 2015, 92, 220414.

[14] S. Gomez Graña, A. Le Beulze, M. Treguer Delapierre, S. Mornet, E. Duguet, E. Grana, E. Cloutet, G. Hadziioannou, J. Leng, J. B. Salmon, V. G. Kravets, A. N. Grigorenko, N. A. Peyyety, V. Ponsinet, P. Richetti, A. Baron, D. Torrent, P. Barois, Mater. Horiz. 2016, 3, 596.

[15] S. Jahani, Z. Jacob, Nat. Nanotechnol. 2016, 11, 23.

[16] D. E. Aspnes, A. A. Studna, Phys. Rev. B 1983, 27, 985.

[17] D. T. Pierce, W. E. Spicer, Phys. Rev. B 1972, 5, 3017.

[18] P. B. Johnson, R. W. Christy, Phys. Rev. B 1972, 6, 4370.

[19] A. B. Evlyukhin, C. Reinhardt, A. Seidel, B. S. Luk'yanchuk, B. N. Chichkov, Phys. Rev. B 2010, 82, 045404.

[20] A. I. Kuznetsov, A. E. Miroshnichenko, Y. H. Fu, J. B. Zhang, B. Luk'yanchuk, Sci. Rep. 2012, 2, 492.

[21] L. T. Canham, Appl. Phys. Lett. 1990, 57, 1046.

[22] M. Ashuri, Q. He, L. L. Shaw, Nanoscale 2016, 8, 74.

[23] I. Sychugov, J. Valenta, J. Linnros, Nanotechnology 2017, 28, 072002.

[24] C. Huang, S. Shu Qing, Chin. Phys. B 2014, 23, 088102.

[25] A. Venuta, J. Wolfram, H. Shen, M. Ferrari, J. Mater. Chem. B 2017, 5, 207.

[26] X. Cheng, S. B. Lowe, P. J. Reece, J. J. Gooding, Chem. Soc. Rev. 2014, 43, 2680 .

[27] W. Cai, V. Shalaev, Optical Metamaterials, Springer, New York, 2010. DOI: https://doi.org/10.1007/978 1441911513.

[28] P. D. Terekhov, K. V. Baryshnikova, Y. A. Artemyev, A. Karabchevsky, A.S. Shalin, A. B. Evlyukhin, Phys. Rev. B 2017, 96, 035443 .

[29] G. Mie, Ann. Phys. 1908, 25, 377.

[30] C. F. Bohren, D. R. Huffman, Absorption and Scattering of Light by Small Particles, Wiley Interscience, New York, 1983.

[31] A. B. Evlyukhin, S. M. Novikov, U. Zywietz, R. L. Eriksen, C. Reinhardt, S. I. Bozhevolnyi, B. N. Chichkov, Nano Lett. 2012, 12,3749 .

[32] I. Staude, A. Miroshnichenko, M. Decker, N. Fofang, S. Liu, E. Gonzales, J. Dominguez, T. S. Luk, ACS Nano 2013, 7, 7824.

[33] U. Zywietz, A. B. Evlyukhin, C. Reinhardt, B. N. Chichkov, Nat. Commun. 2014, 5, 3402.

[34] P. A. Dmitriev, S. V. Makarov, V. A. Milichko, I. S. Mukhin, A. S. Gudovskikh, A. A. Sitnikova, A. K. Samusev, A. E. Krasnok, P. A. Belov, Nanoscale 2016, 8, 5043.

[35] L. Shi, J. Harris, R. Fenollosa, I, Rodriguez, X. Lu, B. A. Korgel, F. Meseguer, Nat. Commun. 2013, 4, 1904.

[36] J. S. Oh, W. G. Shim, J. W. Lee, F. J. H. Kim, H. Moon, G. Seo, J. Chem. Eng. Data 2003, 48, 1458.

[37] U. Khalilov, G. Pourtois, A. Bogaerts, A. C. T. van Duinc, E. C. Neytsa, Nanoscale 2013, 5, 719. 
[38] X. Lu, K. J. Anderson, P. Boudjouk, B. A. Korgel, Chem. Mater. 2015, 27, 6053.

[39] Z. Bao, M. R. Weatherspoon, S. Shian, Y. Cai, P. D. Graham, S. M. Allan, G. Ahmad, M. B. Dickerson, B. C. Church, Z. Kang, H. W. Abernathy III, C. J. Summers, M. Liu, K. H. Sandhage, Nature 2007, 446, 172.

[40] J. F. Wang, K. X. Wang, F. H. Du, X. X. Guo, Y. M. Jiang, J. S. Chen, Chem. Commun. 2013, 49, 5007.

[41] W. Deqing, S. J. Ziyuan, J. Mater. Synth. Process. 2001, 9, 241.

[42] T. D. Nguyen, W. Y. Hamad, M. J. MacLachlan, Chem. Mater 2016, 28, 2581.

[43] J. K. Yoo, J. Kim, M. J. Choi, Y. U. Park, J. Hong, K. M. Baek, K. Kang, Y. S. Jung, Adv. Energy Mater. 2014, 4, 1400622.

[44] M. Ibisate, D. Golmayo, C. López, Adv. Mater. 2009, 21, 2899.

[45] M. Dasog, Z. Yang, J. G. C. Veinot, CrystEngComm 2012, 14, 7576.

[46] D. Qiu, G. Bu, B. Zhao, Z. Lin, J. Solid State Electrochem. 2015, $19,935$.

[47] J. Xie, G. Wang, Y. Huo, S. Zhang, G. Cao, X. Zhao, Electrochim. Acta 2014, 135, 94.

[48] K. Chen, Z. Bao, J. Shen, G. Wu, B. Zhou, K. H. Sandhage, J. Mater. Chem. 2012, 22, 16196.

[49] Z. Bao, E. M. Ernst, S. Yoo, K. H. Sandhage, Adv. Mater. 2009, 21,474 .

[50] R. Gresback, T. Nozaki, K. Okazaki, Nanotechnology 2011, 22, 305605 .

[51] L. Mangolini, E. Thimsen, U. Kortshagen, Nano Lett. 2005, 5, 655.

[52] A. Bapat, C. Anderson, C. Perrey, C. Carter, S. A. Campbell, U. Kortshagen, Plasma Phys. Controlled Fusion 2004, 46, B97.

[53] O. Yasar Inceoglu, T. Lopez, E. Farshihagro, L. Mangolini, Nanotechnology 2012, 23, 255604.

[54] S. Guruvenket, J. M. Hoey, K. J. Anderson, M. T. Frohlich, R. Krishnan, J. Sivaguru, M. P. Sibi, P. Boudjouk, J. Mater. Chem. 2016, 4, 8206.

[55] X. Li, Y. He, S. S. Talukdar, M. T. Swihart, Langmuir 2003, 19, 8490.

[56] M. L. Ostraat, J. W. De Blauwe, M. L. Green, L. D. Bell, H. A. Atwater, R. C. Flagan, J. Electrochem. Soc. 2001, 148, G265.

[57] D. M. Holunga, R. C. Flagan, H. A. Atwater, Ind. Eng. Chem. Res. 2005, 44, 6332.

[58] R. Körmer, M. P. M. Jank, H. Ryssel, H. J. Schmid, W. Peukert, J. Aerosol Sci. 2010, 41, 998.

[59] R. Körmer, B. Butz, E. Spiecker, W. Peukert, Cryst. Growth Des. 2012, 12, 1330.

[60] M. K. Alam, R. C. Flagan, Aerosol Sci. Technol. 1986, 5, 237.

[61] H. Shirai, Y. Fujimura, S. Jung, Thin Solid Films 2002, $12,407$.

[62] X. Q. Yan, D. F. Liu, L. J. Ci, J. X. Wang, Z. P. Zhou, H. J. Yuan, L. Song, Y. Gao, L. F. Liu, W. Y. Zhou, G. Wang, S. S. Xie, J. Cryst. Growth 2003, 69, 257.

[63] R. Fenollosa, F. Meseguer, M. Tymczenko, Adv. Mater. 2008, 20, 95.

[64] L. Shi, T. U. Tuzer, R. Fenollosa, F. Meseguer, Adv. Mater. 2012, $24,5934$.

[65] G. Philippot, C. Elissalde, M. Maglione, C. Aymonier, Adv. Powder Technol. 2014, 25, 1415.

[66] C. Aymonier, A. Loppinet Serani, H. Reverón, Y. Garrabos, F. Cansell, J. Supercrit. Fluids 2006, 38, 242.

[67] Y. Roig, S. Marre, T. Cardinal, C. Aymonier, Angew. Chem. Int. Ed. 2011, 50,12071; Angew. Chem. 2011, 123, 12277.

[68] B. Giroire, C. Slostowski, S. Marre, C. Aymonier, T. Aida, D. Hojo, N. Aoki, S. Takami, T. Adschiri, Phys. Chem. Chem. Phys. 2016, 18, 1727.

[69] J. A. Darr, J. Zhang, N. M. Makwana, X. Weng, Chem. Rev. 2017, 117, 11125 .

[70] J. D. Holmes, K. J. Ziegler, R. C. Doty, L. E. Pell, K. P. Johnston, B. A. Korgel, J. Am. Chem. Soc. 2001, 123, 3743.
[71] L. E. Pell, A. D. Schricker, F. V. Mikulec, B. A. Korgel, Langmuir 2004, 20, 6546.

[72] J. T. Harris, J. L. Hueso, B. A. Korgel, Chem. Mater. 2010, 22, 6378.

[73] J. R. Heath, Science 1992, 258, 1131.

[74] J. Liang, X. Li, Q. Cheng, Z. Hou, L. Fan, Y. Zhu, Y. Qian, Nanoscale 2015, 7, 3440.

[75] L. Wang, N. Lin, J. Zhou, Y. Zhu, Y. Qian, Chem. Commun. $\mathbf{2 0 1 5}, 51,2345$.

[76] N. Lin, Y. Han, J. Zhou, K. Zhang, T. Xu, Y. Zhu, Y. Qian, Energy Environ. Sci. 2015, 8, 3187.

[77] N. Lin, Y. Han, L. Wang, J. Zhou, J. Zhou, Y. Zhu, Y. Qian, Angew. Chem. Int. Ed. 2015, 54,3822; Angew. Chem. 2015, 127, 3893.

[78] X. Liu, C. Giordano, M. Antonietti, J. Mater. Chem. 2012, 22, 5454.

[79] D. Neiner, H. W. Chiu, S. M. Kauzlarich, J. Am. Chem. Soc. 2006, 128, 11016.

[80] R. A. Bley, S. M. Kauzlarich, J. Am. Chem. Soc. 1996, 118, 12461.

[81] S. Tang, H. Zhao, RSC Adv. 2014, 4, 11251.

[82] M. Zobel, Ph.D. thesis, Nanoparticles crystallization and solvent interface restructuring especially for $\mathrm{ZnO}$ nanoparticles in organic solvents, Friedrich Alexander Universität Erlangen Nurnberg, 2015.

[83] R. K. Baldwin, K. A. Pettigrew, E. Ratai, M. P. Augustine, S. M. Kauzlarich, Chem. Commun. 2002, 1822.

[84] R. K. Baldwin, K. A. Pettigrew, J. C. Garno, P. P. Power, G. Y. Liu, S. M. Kauzlarich, J. Am. Chem. Soc. 2002, 124, 1150.

[85] N. T. K. Thanh, N. Maclean, S. Mahiddine, Chem. Rev. 2014, 114,7610 .

[86] Y. Chen, G. Yang, R. Zhao, W. Xue, China Funct. Mater. Technol. Ind. Forum 2014, 180, 809.

[87] H. Y. Tuan, B. A. Korgel, Chem. Mater. 2008, 20, 1239.

[88] J. Zou, S. Kauzlarich, J. Cluster Sci. 2008, 19, 341.

[89] M. H. Balci, R. Sæterli, J. Maria, M. Lindgren, R. Holmestad, T. Grande, M. A. Einarsrud, Dalton Trans. 2013, 42, 2700.

[90] M. H. Balci, J. Maria, F. Vullum Bruer, M. Lindgren, T. Grande, M. A. Einarsrud, J. Cluster Sci. 2012, 23, 421.

[91] S. P. Ashby, J. A. Thomas, P. R. Coxon, M. Bilton, R. Brydson, T. J. Pennycook, Y. Chao, J. Nanopart. Res. 2013, 15, 1425.

[92] J. P. Wilcoxon, G. A. Samara, Appl. Phys. Lett. 1999, 74, 3164.

[93] N. Shirahata, S. Furumi, Y. Sakka, J. Cryst. Growth 2009, 311, 634.

[94] R. D. Tilley, J. H. Warner, K. Yamamoto, I. Matsui, H. Fujimori, Chem. Commun. 2005, 1833.

[95] J. Zou, P. Sanelle, K. A. Pettigrew, S. M. Kauzlarich, J. Cluster Sci. 2006, 17, 565.

[96] M. Niederberger, H. Colfen, Phys. Chem. Chem. Phys. 2006, 8, 3271.

[97] P. A. Dmitriev, S. V. Makarov, V. A. Milichko, I. S. Mukhin, A. M. Mozharov, A. A. Sitnikova, A. K. Samusev, A. E. Krasnok, P. A. Belov, J. Phys. Conf. Ser. 2016, 690, 012020.

[98] "Sintering of Ceramics": L. C. De Jonghe, M. N. Rahaman, Handbook of Advanced Ceramics (Ed.: S. Somiya), Elsevier, Amsterdam, 2003, Chap. 4.

[99] A. Carretero Genevrier, M. Gich, L. Picas, J. Gazquez, G. L. Drisko, C. Boissiere, D. Grosso, J. Rodriguez Carvajal, C. Sanchez, Science 2013, 340, 827.

[100] W. Knaepen, C. Detavernier, R. L. Van Meirhaeghe, J. J. Sweet, C. Lavoie, Thin Solid Films 2008, 516, 4946.

[101] G. L. Drisko, A. Carretero Genevrier, A. Perrot, M. Gich, J. Gazquez, J. Rodriguez Carvajal, L. Favre, D. Grosso, C. Boissiere, C. Sanchez, Chem. Commun. 2015, 51, 4164.

[102] "Advanced Topics in Crystallization": D. N. Lee, S. B. Lee, Solid Phase crystallization of amorphous silicon films (Ed.: Y. 
Mastai), InTech, London, 2015, Chap. 9, ISBN 97895351 21251.

[103] G. L. Drisko, A. Carretero Genevrier, M. Gich, J. Gàzquez, D. Ferrah, D. Grosso, C. Boissiere, J. Rodriguez Carvajal, C. Sanchez, Adv. Funct. Mater. 2014, 24, 5494.

[104] S. R. Wilson, C. W. White, P. P. Pronko, R. T. Young, B. R. Appleton, AIP Conf. Proc. 1979, 50, 351.

[105] S. K. Sundaram, E. Mazur, Nat. Mater. 2002, 1, 217.

[106] T. Y. Choi, D. J. Hwang, C. P. Grigoropoulos, Opt. Eng. 2003, $42,3383$.

[107] J. M. Shieh, Z. H. Chen, B. T. Dai, Y. C. Wang, A. Zaitsev, C. L. Pan, Appl. Phys. Lett. 2004, 85, 1232.

[108] J. Yun, J. Huang, A. Teal, K. Kim, S. Varlamov, M. A. Green, Thin Solid Films 2016, 609, 12.

[109] X. Ji, S. Lei, S. Y. Yu, H. Y. Cheng, W. Liu, N. Poilvert, Y. Xiong, I. Dabo, S. E. Mohney, J. V. Badding, V. Gopalan, ACS Photonics 2017, 4, 85 .

[110] V. P. Belik, O. S. Vasyutinskii, A. V. Kukin, M. A. Petrov, R. S. Popov, E. I. Terukov, Tech. Phys. Lett. 2016, 42, 788.

[111] S. Jin, S. Hong, M. Mativenga, B. Kim, H. H. Shin, J. K. Park, T. W. Kim, J. Jang, Thin Solid Films 2016, 616, 838.

[112] J. Očenášek, P. Novák, L. Prušáková, Appl. Surf. Sci. 2017, 392, 867.

[113] N. Healy, M. Fokine, Y. Franz, T. Hawkins, M. Jones, J. Ballato, A. C. Peacock, U. J. Gibson, Adv. Opt. Mater. 2016, 4, 1004.

[114] J. Qiu, W. Shen, R. Yu, B. Yao, Chem. Lett. 2008, 37, 644.

[115] L. Wang, N. Lin, J. Zhou, Y. Zhu, Y. Qian, Chem. Commun. $\mathbf{2 0 1 5}, 51,23545$.

[116] Y. Chen, Y. Chen, Microelectron. Eng. 2001, 57 58, 897.

[117] B. H. Kim, M. A. Pamungkas, M. Park, G. Kim, K. R. Lee, Y. C. Chung, Appl. Phys. Lett. 2011, 99, 143115.

[118] D. B. Kao, J. P. McVittie, W. D. Nix, K. C. Saraswat, IEEE Trans. Electron. Devices 1988, 35, 25.

[119] Y. Yu, C. E. Rowland, R. D. Schaller, B. A. Korgel, Langmuir $\mathbf{2 0 1 5}, 31,6886$.
[120] J. M. Buriak, Chem. Rev. 2002, 102, 1271 .

[121] J. G. C. Veinot, Chem. Commun. 2006, 4160.

[122] M. Dasog, J. Kehrle, B. Rieger, J. G. C. Veinot, Angew. Chem. Int. Ed. 2016, 55, 2322; Angew. Chem. 2016, 128, 2366.

[123] B. Ghosh, N. Shirahata, Sci. Technol. Adv. Mater. 2014, 15, 014207.

[124] X. Li, Y. He, M. T. Swihart, Langmuir 2004, 20, 4720.

[125] J. Rinck, D. Schray, C. Kübel, A. K. Powell, G. A. Ozin, Small $\mathbf{2 0 1 5}, 11,335$.

[126] N. Vogel, M. Retsch, C. A. Fustin, A. del Campo, U. Jonas, Chem. Rev. 2015, 115, 6265.

[127] H. Ahire, Q. Wang, P. R. Coxon, G. Malhotra, R. Brydson, R. Chen, Y. Chao, ACS Appl. Mater. Interfaces 2012, 4, 3285.

[128] R. D. Tilley, K. Yamamoto, Adv. Mater. 2006, 18, 2053.

[129] J. H. Warner, A. Hoshino, K. Yamamoto, R. D. Tilley, Angew. Chem. Int. Ed. 2005, 44, 4550; Angew. Chem. 2005, 117, 4626.

[130] P. Das, A. Saha, A. R. Maity, S. C. Rayb, N. R. Jana, Nanoscale 2013, 5, 5732 .

[131] P. K. Sudeep, Z. Page, T. Emrick, Chem. Commun. 2008, 6126.

[132] X. Cheng, R. Gondosiswanto, S. Ciampi, P. J. Reece, J. J. Gooding, Chem. Commun. 2012, 48, 11874.

[133] M. Rosso Vasic, E. Spruijt, B. van Lagen, L. De Cola, H. Zuilhof, Small 2008, 4, 1835.

[134] S. Chatterjee, T. K. Mukherjee, J. Phys. Chem. C 2013, 117, 10799.

[135] Y. Yu, C. A. Bosoy, C. M. Hessel, D. M. Smilgies, B. A. Korgel, ChemPhysChem 2013, 14, 84.

[136] J. Xiang, J. Li, H. Li, C. Zhang, Q. Dai, S. Tie, S. Lan, Opt. Express 2016, 24, 11420. 